
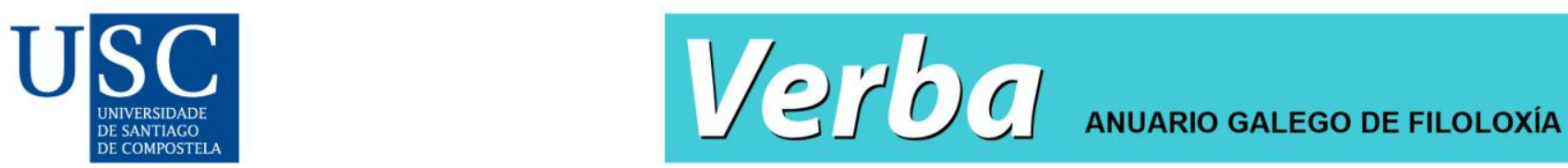

Verba: Anuario Galego de Filoloxía, 48, 2021. ISSN: 2174-4017

https://doi.org/10.15304/verba.48.6758

Artículos

\title{
Los doze trabajos de Hércules (1417) de Enrique de Villena: continuidades estilísticas y codificación fraseológica*
}

Enrique de Villena's Los doze trabajos de Hércules (1417):

stylistic continuity and phraseological standardization

Santiago Vicente Llavata ${ }^{1}$

1Universitat de València, España

Recibido: 17/04/2020; Aceptado: 28/06/2020

\section{Resumen}

Este artículo pretende contribuir al conocimiento de la fraseología medieval hispánica a partir del estudio de las locuciones en Los doze trabajos de Hércules (1417), de Enrique de Villena. En concreto, se pretende trazar la trayectoria histórica de las combinaciones fraseológicas en una compañía e de un coraçón, con mano fuerte, a consejo e induzimiento de y a pro e acresçentamiento de / por acresçentamiento de / por cresçimiento de, con el fin de delimitar los modelos prosísticos en que se basó Villena, con su consiguiente contribución hacia la progresiva codificación de estas unidades. Para ello, partimos de la línea de investigación diseñada por Echenique (2003) a la hora de abordar el estudio histórico de estas secuencias lexicalizadas, caracterizadas por su idiomaticidad, fijeza y expresividad. Con ello se intenta demostrar la existencia de ciertas continuidades estilísticas entre Los doze trabajos de Hércules y la prosa medieval hispánica de signo historiográfico, con una atención especial en el ámbito de la Corona de Aragón y en la tradición narrativa de materia troyana.

Palabras clave: fraseología medieval hispánica; literatura castellana del siglo xv; Enrique de Villena; prosa historiográfica; Corona de Aragón; materia de Troya.

\section{Abstract}

This article aims to contribute to the knowledge of medieval Hispanic phraseology by means of the study of the phraseological units which are represented in Enrique de Villena's Los doze trabajos de Hércules (1417). More specifically, this contribution describes the history of the idioms en una compañía e de un coraçón, con mano fuerte, a consejo e induzimiento de, a pro e acresçentamiento de / por acresçentamiento de / por cresçimiento de, in order to delimit the prose models Villena based himself on and to assess his to the gradual standardization of these units. To achieve this aim, this study follows Echenique's (2003) line of research, in order to deal with the historical analysis of these lexicalizated sequences, characterized by its idiomaticity, fixation and expressivity. This is intended to verify the existence of a certain stylistic continuity 
between Los doze trabajos de Hércules and the medieval Hispanic historical prose, with special attention on the domain of the Crown of Aragon and on the narrative tradition of the matter of Troy.

Keywords: medieval Hispanic phraseology; Castilian 15th century literature; Enrique de Villena; historical prose; Crown of Aragon; Matter of Troy

\section{BREVE ESTADO DE LA CUESTIÓN E HIPÓTESIS DE TRABAJO}

Los dotze treballs d'Hèrcules, obra redactada en catalán, supone la primera creación literaria de Enrique de Villena1. Compuesta en abril de 1417 a instancia del caballero valenciano mosén Pere Pardo de la Casta, hombre influyente de la corte y consejero del rey Alfonso V el Magnánimo, Villena la autotradujo ${ }^{2}$ a la lengua castellana en septiembre de ese mismo año, con algunas adiciones y comentarios, si bien, como indica Cátedra (1994: XX), no tanto como parece sugerir el autor en el prólogo. En ella, Villena evoca, desde una posición exegética, los doce trabajos del héroe griego con una finalidad clara: propiciar un conjunto de enseñanzas morales a la sociedad de su tiempo y, en especial, al estamento de los caballeros, a través de los hechos gloriosos del personaje mítico: "Así será espejo actual a los gloriosos cavalleros en armada cavallería, moviendo el coraçón de aquéllos en non dubdar los ásperos fechos de las armas e emprender grandes e honrados partidos, enderesçándose a sostener el bien común, por cuya razón cavallería fue fallada" (Cátedra 2007: 16).

En el repaso de la bibliografía asociada al desentrañamiento de las claves textuales que encierra Los doze trabajos de Hércules, hay que destacar la atención limitada que ha suscitado el estudio de este texto desde un punto de vista filológico. Así, junto a la aportación de Morreale (1954 y 1958), Cátedra (1981, 1988, 1994 y 2002) ha estudiado con profundidad la obra literaria de Enrique de Villena en su conjunto y, en lo que respecta a esta primera creación, con un análisis esclarecedor de sus condiciones de producción. Por su parte, Ridruejo (1984) analizó tres construcciones del catalán y del aragonés registradas en la opera prima de Villena 3 .

Ciertamente, las coordenadas vitales de este escritor invitan a acercarse a su obra literaria como un espacio propicio para el estudio filológico de las vías de comunicación cultural en el marco amplio de la historia lingüística hispánica, por cuanto en su propia biografía se concitan avatares destacados que apuntan a un contacto continuado con la Corona de Aragón a lo largo de su trayectoria vital y artística. Nieto de Enrique II de Castilla por parte de madre y bisnieto de Pedro IV de Aragón por parte de padre, pasó su infancia en la corte ducal de Gandía al cuidado de su abuelo don Alfonso de Aragón, primer marqués de Villena, condestable de Castilla y duque de Gandía. En ella, tuvo contacto directo con la familia March, pero también con figuras literarias de primer orden, como Francesc Eiximenis o Antoni Canals. Su estancia en la corte ducal de Gandía le proporcionó también la posibilidad de estar presente en algunos de los actos más significativos de la corte de Juan I y, posteriormente, del rey Martín I “el Humano”, donde pudo enriquecerse con el aprendizaje de las tradiciones poéticas de raíz occitana, así como sumergirse en la cultura cancilleresca que se abría paso, y en cuyo marco la recepción de los autores clásicos y el interés por la retórica constituían las señas de identidad de estos nuevos aires de pensamiento (Cátedra 1994).

En el marco de este amplio universo cultural y geográfico en que se desarrolla el quehacer literario de Enrique de Villena, a caballo entre la Corona de Castilla y la Corona de Aragón, este artículo pretende adentrarse en el análisis estilístico de la fraseología empleada en Los doze 
trabajos de Hércules, ya delineado en publicaciones anteriores (Vicente Llavata, 2019c y 2020b). En concreto, centraremos la atención en trazar la trayectoria histórica de las combinaciones locucionales en una compañía e de un coraçón, con mano fuerte, a consejo e induzimiento de y a pro e acresçentamiento de / por acresçentamiento de / por cresçimiento de ${ }^{4}$, con el fin de delimitar los modelos prosísticos en que se basó Villena a la hora de emplearlas en su obra, con su consiguiente contribución hacia su progresiva codificación. Para tal finalidad, partimos de la línea de investigación diseñada por Echenique (2003), que se enmarca y se inspira en esta reflexión formulada por Rafael Lapesa, en un diálogo en el tiempo entre la continuidad y la renovación de las formas de expresión literaria, entre las que cabe integrar la fraseología en calidad de testimonio fehaciente del componente dinámico del lenguaje:

La fraseología es una de las manifestaciones primitivas y a la vez más perdurables de la creación artística del lenguaje transmitida por vía oral. Actividad y producto intermedio entre lo meramente lingüístico y las formas elementales de la literatura tradicional, la fraseología presenta, como éstas, asombrosa continuidad en medio de su incesante renovación: son muchas las locuciones que se perpetúan con fluidez formal y aparición escrita ininterrumpida desde la Edad Media o el siglo XVI hasta ahora. Pero también hay casos de perduración en estado latente" (Lapesa 1992 [1980]: 85).

En el estudio introductorio que acompaña a su edición, Morreale (1958: XXVI-XXXVI) fijó las fuentes que Villena utilizó para la redacción de su opera prima. Como modelos textuales relevantes en que se inspiró para "compilar y vulgarizar" sus historias, señala a autores de la Antigüedad clásica como Tolomeo, Lucano, Suetonio, Ovidio, Virgilio, Séneca o Boecio; estos últimos muy presentes en la secuenciación de los contenidos de la obra considerada. De hecho, Morreale (1958: XXXI-XXXII) destaca la presencia llena de significado del Séneca trágico con sus obras Hercules furens y Hercules oetaeus, y se pregunta, en términos de una posible continuidad estilística, si este autor "ejerció alguna influencia en el léxico de Los doze trabajos, por su afición a las palabras compuestas y abuso de los sufijos, o por las muchas figuras retóricas, que dan a sus versos un ornato a veces excesivo".

Pero más allá de las huellas de estos autores clásicos, hay que destacar el armazón conceptual en que se asienta el texto de Los doze trabajos de Hércules, que no es otro que el de la exégesis basada en la alegoría, en el sentido en que la entienden los comentaristas antiguos Fulgencio, Macrobio o San Isiodoro; una interpretación alegórica enraizada en los ideales éticos de la filosofía estoica y neoplatónica. En este sentido, la obra que nos ocupa supone el primer ensayo de exégesis mitológica en el ámbito hispánico, tal como destacó en su día Morreale (1954). En el marco, pues, de esta línea de pensamiento, a Villena interesa, ante todo, la noción de "narración fabulosa" empleada por Macrobio ${ }^{5}$, caracterizada por recrear la verdad histórica en el marco de una ficción lícita, cimentada sobre la base de la invención poética6. Y esta verdad sustancial se opondrá a la fábula o ficción poética presente en los relatos mitológicos, criticados por este poeta antiguo por su obscenidad y falta de moralidad (Morreale 1958: XII).

Precisamente, este debate entre ambos modos posibles de vehicular las ideas en el ámbito artístico - "verdad histórica" frente a "verdad alegórica" - también está presente en la propia tradición narrativa de la materia de Troya7, donde se librará una batalla intelectual en pleno siglo XV entre quienes defienden la superioridad de la supuesta verdad histórica contenida en las fuentes historiográficas De excidio Troiae (s. vI d.C.) de Dares y Ephemeris belli Troiani (s. IV d.C.) de Dictis y, especialmente, en la Historia destructionis Troiae (c. 1287) de Guido delle Colonne, frente a la 
verdad alegórica, caracterizada por su artificiosidad, y simbolizada en la figura de Homero (Peláez Benítez 1999: 59-65).

Es en este ámbito compartido de ideas donde creemos percibir una coincidencia entre las preferencias artísticas de Enrique de Villena y los autores medievales que cultivaron la "verdad histórica" en sus narraciones fabulosas, entre quienes sobresale Guido delle Colonne a la hora de recrear el mito de Troya hacia el último cuarto del siglo XIII ${ }^{8}$. Morreale (1958: XVIII-XIX) destaca así la importancia del autor mesinés y de su obra historiográfica en el marco amplio de la cultura de Occidente en el contexto de la Baja Edad Media:

Por otra parte, es propio del género poético hacer que lo narrado parezca fabuloso; así lo enseñaba, entre otros, el gran maestro de la historiografía medieval Guido delle Colonne, quien bajo el ropaje de la invención poética cree percibir la "pura y sencilla verdad de la historia" ("eius ystorie puram et simplicem ueritatem in uersuta uestigia uariauit, fingens multa non fuerunt et que fuerunt aliter transformando" [...] Villena conocía esta importante obra [la Historia destructionis Troiae], que cita varias veces en el Tratado de la consolación.

Estas palabras de Morreale resultan de primera importancia para el objetivo fundamental de este artículo y suponen, en buena medida, el punto de partida de nuestra hipótesis de trabajo ${ }^{9}$, que planteamos en estos términos: dada la íntima conexión existente en el modo de concebir la comunicación literaria que Villena comparte con los "esponedores" medievales y, en particular, con Macrobio, y constatada la persistencia de ciertos módulos de expresión idiomática en el texto que nos ocupa y en la tradición narrativa de materia troyana, se pretende comprobar hasta qué punto se atisba una cierta continuidad estilística entre Los doze trabajos de Hércules (1417) y las versiones en castellano, catalán y aragonés que traducen la Historia destructionis Troiae ${ }^{10 .}$

Este artículo pretende contribuir, pues, al conocimiento de la fraseología medieval hispánica con la atención puesta en un conjunto limitado de locuciones en Los doze trabajos de Hércules. Así, a partir del análisis estilístico de la fraseología en la opera prima de Enrique de Villena en su contraste con la prosa medieval hispánica de signo historiográfico — con una incidencia especial en el ámbito cultural de la Corona de Aragón y en la tradición narrativa de materia troyana ${ }^{11}$-, se pretende esbozar un hito significativo en la historia de las vías de comunicación cultural y lingüística en el ámbito hispánico.

\section{ESTUDIO DE LAS COMBINACIONES LOCUCIONALES EN LOS DOZE TRABAJOS DE HÉRCULES: CONTINUIDADES ESTILÍSTICAS Y CODIFICACIÓN FRASEOLÓGICA}

\subsection{En una compañía e de un coraçón y sus variantes fraseológicas}

En el marco del quinto trabajo herculino, en el que el héroe mítico vence al can Cerbero que custodia la entrada al infierno ${ }^{12}$, Villena emplea la combinación fraseológica en una compañía e de un coraçón:

Ércules, domador de las fieras, satisfaziendo a la nesçesidat e ruegos de aquéllos, doliéndose si peligrasen, con ellos a los infiernos non dubdó de desçender. E así andando en una compañia e de un coraçón, cuando fueron 
a la entrada de la infernal çibdat, el can espantable devoró e comió a Periteo, que se adelantó mucho, non esperando los otros, por entrar (Cátedra 2007: 40).

En el contexto significativo de este trabajo, se narra el rapto de Proserpina por parte del dios Pluto, que es hija de la diosa Ceres, divinidad que simboliza el arte de la labranza. Teseo, que quiere casarse con ella, emprende una acción guerrera para tratar de rescatar a su amada. Para ello, además de contar con la ayuda de Periteo, un joven noble, solicita la ayuda de Hércules, quien acepta de buen grado. En el desenlace de la historia, Hércules consigue reducir al espantable perro de tres cabezas. Como puede comprobarse, la unidad en una compañía e de un coraçón resulta una complementación sintáctica de la forma verbal andando, y presenta un valor semántico modal, orientado a destacar la fortaleza y posición unánime de voluntad de los tres guerreros frente al conflicto que les aguarda.

De acuerdo con los datos del Corpus diacrónico del español (CORDE), la secuencia locucional en una compañía e de un coraçón no se registra en la documentación de la lengua castellana. Si se realiza una búsqueda del segmento /en una compañía/, el banco de datos de la Real Academia Española nos ofrece cinco casos, de los cuales tres de ellos resultan de naturaleza fraseológica, si bien su cronología es posterior tanto a la fecha de composición de nuestro texto (1417) como a la datación de las versiones peninsulares de materia troyana consideradas en este estudio, fechadas estas últimas en un tramo temporal que abarca desde el último cuarto del siglo XIV hasta mediados del siglo XV. Así, los tres casos que ofrece el CORDE, datados dos de ellos con anterioridad a 1500 y el restante en 1528, presentan un significado prácticamente idéntico al que se aprecia en nuestro texto:

Los cavalleros de Medina que, non menos deseosos de ganar sus honras, ivan juntos en una compañía como primero fueron, caminaron. E aquí no se pone persona principal que de la villa saliese con la gente porque todos los cavalleros eran casi iguales \&, sobre qual seria capitan, ovieron muchas divisiones [...] (Alfonso López de Lezana, Tratado de las armas de Pedro de Ávila, anterior a 1500).

Sin embargo, una búsqueda con la forma gráfica arcaica <companna> nos ofrece datos documentales desde la segunda mitad del siglo XIII. Así, se puede apuntar la plasmación de sintagmas prepositivos con núcleo companna, como entre grand companna de omnes (Lapidario, [c. 1250]), de toda la companna de los christianos (Fuero Juzgo [c. 1250-1260]), con toda su companna, en su companna o de so companna (Estoria de España [1270-1284]).

Igualmente, el registro de la secuencia locucional de un coraçon presenta también una historicidad marcada. Se registra en 25 ocasiones desde la segunda mitad del siglo XIII en la documentación castellana ${ }^{13}$. En el análisis de esos 25 casos se pueden apreciar ciertas tendencias gramaticales comunes. Así, si bien en algún caso puntual la combinación se presenta en su forma escueta de un coraçon, como en las primeras documentaciones en que se registra, fechadas hacia 1250, y pertenecientes a El nuevo testamento según el manuscrito escurialense I-j-6 ("e entraron acedada mientre de un coraçon a un logar o iudgauan los ombres [...]"), en la mayor parte de los registros del CORDE esta secuencia locucional se completa con otros componentes léxicos, por lo que no se sabe hasta qué punto estas piezas léxicas y segmentos prepositivos se integran o no en el proceso global de lexicalización de la unidad (Vicente Llavata 2021).

Uno de los componentes léxicos que suele aparecer con más frecuencia junto al sintagma lexicalizado de un coraçon es el cuantificador todos, con una función ponderativa o escalar, como puede apreciarse en este fragmento, extraído también del manuscrito escurialense anteriormente 
citado: "E estauan todos de un coraçon en el portal de Salomon". Sin embargo, a pesar de ese aparente principio de fijación entre ambos componentes, todo parece indicar que las posibilidades sintácticas en el seno de tal secuencia son variadas, si tenemos presente el ejemplo siguiente de la cuarta parte de la General Estoria, donde se registra la inserción de un adverbio -mente entre ambos componentes: "\& lidiauan todos esforçadamientre de un coraçon"; inserción que no se limita a esta etapa inicial de desarrollo de las estructuras morfosintácticas, caracterizada por la agregación simultánea de diferentes componentes en torno a la voz nuclear de la secuencia locucional en cuestión (Echenique Elizondo 2018: 424), sino que tales inserciones se proyectan más allá, como puede apreciarse en este ejemplo extraído de El Victorial, de Gutierre Díaz de Games, fechado entre 1431 y 1449: "Estad todos firmes de un coraçón, que por fuyr non podredes escapar".

En esta misma línea, también parece admitir la secuencia en vías de lexicalización (todos) de un coraçón la libertad posicional de sus componentes, como en el ejemplo siguiente, extraído de la primera parte de la Grant Crónica de Espanya (1385) patrocinada por Juan Fernández de Heredia ${ }^{14}$, en el que se constata la posposición del cuantificador todos con respecto al segmento de un coraçon: "\& porque fuessen de un coraçon todos \& de una uoluntat algunos pocos qui eran fincados [...]" (fol. $399 v)^{15}$.

Más allá de la estructura gramatical articulada en torno al sintagma prepositivo de un coraçón, la documentación representada en CORDE recoge una secuencia locucional compleja, basada en una expansión sintáctica en forma de yuxtaposición: "e así poderían ellos rogar a los tribunos que todos, de un coraçón en uno con los cónsules, quisiesen que la guerra fuesse echada al lueñe dellos [...]" (Pero López de Ayala, Traducción de las Décadas de Tito Livio, fechado hacia 1400). En ella, a la secuencia en vías de lexicalización todos de un coraçón se yuxtapone o agrega el sintagma en uno, semánticamente afín a aquel.

Precisamente, en aquella muestra herediana presentada se registraba otra variación en forma de expansión sintáctica, basada en la adición del segmento de una uoluntat. Incluso, en el seno de esta primera parte de la Grant Crónica de Espanya, así como en la Traducción de las vidas semblantes (1379-1384) de Plutarco, se registra otra posibilidad combinatoria en el marco de esta secuencia como es la adición del componente semánticamente afín uoluntat en relación sintáctica de coordinación: "Mas, siempre Clodio empachando todo el consello, de un coraçon e voluntat todo el consello determinó por sentencia que Clodio no fiziesse ninguna nueva ordenacion [...]" (Traducción de las vidas semblantes II, Álvarez Rodríguez 2009: 1351).

Con todo, pese a que dichas expansiones sintácticas pudieran catalogarse como innovaciones estilísticas en el marco de la obra herediana ${ }^{16}$, hay que anotar que el registro de estas secuencias complejas (de un coraçon \& de una uoluntat, de un coraçon \& uoluntat) se da desde mediados del siglo XIII, en cronología paralela a la secuencia de un coraçon. Así, en el Fuero Juzgo (c. 1250-1260), se registra esta unidad: "Assí que mientre fuéremos todos de un coraçón \& de una uoluntat \& de una $f e$, que sea entre nos paz \& justicia en el regno [...]". Como se puede apreciar en el dato aportado, la secuencia locucional registrada es el resultado de la yuxtaposición sintáctica de diferentes conglomerados prepositivos, que presentan como rasgo común el de ser afines semánticamente. Ello es muestra, en definitiva, de que "las locuciones viven en variantes. No son "frases hechas", pues viven rehaciéndose en continua transformación" (Lapesa 1992 [1980]: 85), lo que nos dibuja nítidamente el proceso constitutivo de las locuciones, entendido como la agregación de 
componentes varios "aún sin gramaticalizar" en torno a uno o a varios núcleos, tal como lo ha delineado Echenique Elizondo (2018: 425) ${ }^{17}$.

La documentación medieval catalana ofrece también múltiples posibilidades de combinación sintáctica en torno a la voz nuclear companya / companyia ${ }^{18}$, atestiguadas desde la segunda mitad del siglo XIII en casos como ab tota sa companya, ab tan gran companya, ab companya (d'hòmens de cavayl), gran companya (de cavallers), ab bona companya, gran companya e bona (de cavallers), ab huna companya (de hòmens a cavall), ab molta companya de bons cavallers, ab tota lur/la companyia, ab tanta companyia, ab gran companyia, ab una gran companyia, ab bella companyia, tots de/en companyia, en ma/sa/lur companyia, en la mia/tua/sua companyia, en vostra companyia ${ }^{19}$, entre otras. Hacia finales del XIV se empiezan a documentar asimismo otras secuencias más complejas en vías de lexicalización como ab gran companya e ab gran poder ("Mas vet què és lo món, que per tal com tu fas lo mal públicament, e ab gran companya e ab gran poder, ést apellat emperador [...]", Francesc Eiximenis, Lo crestià, c. 1379-1392) o ab gran poder e ab gran navili ("[...] E tots los reis, amonestats per nós, pendran armes contra los troyans; e ab gran poder e ab gran navili irem tots d'un coratge contra Troya", Jaume Conesa, Històries troianes, 1367-1374).

También el Diccionari-català-valencià-balear recoge en su acepción cuarta 'conjunt de soldats comandats per un caporal subaltern' el sentido de esta voz, así como diferentes pasajes, como en el siguiente de la obra Eximplis: "Ab grans companyes de hòmens d'armes". También en la entrada companyia se recoge el significado relativo al conjunto de soldados dirigidos por un señor feudal, como en el ejemplo perteneciente a la Crònica de Pedro IV de Aragón: "Altres molts richs hòmens e companyies de Castella".

En lo que respecta a la documentación de secuencias lexicalizadas en torno a la voz nuclear cor, el Corpus Informatitzat del Català Antic (CICA) registra cuatro casos de la secuencia compleja d'un cor e d'una voluntat (o volentat), datados todos ellos desde la primera mitad del siglo XIV. La primera mención de esta unidad se localiza en la Crònica (1325-1328) de Ramon Muntaner: "et qui eren tuyt d'un cor et de una volentat; et ella era ab gent trebaylada et qui havien haüt molt de desayre [...]". En calidad de variante fraseológica de esta secuencia, se registra la unidad de un cor $e$ de un voler, documentada en Lo crestià, de Francesc Eiximenis: "[...] emperò, en ço que toca la comunitat sien tots de un cor e de un voler, així que res sots Déu no sia bastant a separar-los d'aquesta unitat e benvolença a la comunitat".

Pues bien, en el contexto prebélico entre aqueos y troyanos, motivado por la ofensa infligida por el rey Laomedonte a Jasón y a Hércules al expulsarlos de su reino, estos solicitan la ayuda de los reyes y príncipes de Grecia para iniciar una acción guerrera contra Troya:

Hercules quasi tocius negocii pondus assumpsit [...]. Non ergo defuit petentibus a Grecorum regibus et ducibus iuuatiua promissio, qui uindictam appetere de commissis a predicto rege Troyano unanimiter omnes probant [...] Qui reges in multa affectione uerborum et in uoluntate non ficta ipsi Herculi predicta unanimiter annuerunt (Guido delle Colonne, Historia destructionis Troiae [c. 1287]. Griffin 1936: 32-34). 
Tabla 1. Combinaciones fraseológicas referidas a la afrenta del rey Laomedonte

\begin{tabular}{|c|c|c|c|}
\hline \multicolumn{4}{|c|}{ Combinaciones fraseológicas referidas a la afrenta del rey Laomedonte } \\
\hline $\begin{array}{l}\text { Històries troianes } \\
\text { (1367-1374) } \\
\text { (Perujo Melgar } \\
\text { 2015: 64-65). }\end{array}$ & $\begin{array}{c}\text { Crónica troyana } \\
(1385-1396) \\
\text { (Sanz Julián 2012: 18) }\end{array}$ & $\begin{array}{l}\text { La corónica troyana } \\
\text { (último cuarto s. XIV) } \\
\text { (Pelletier Norris } \\
\text { 1970: 71) }\end{array}$ & $\begin{array}{c}\text { Libro de la historia } \\
\text { troyana (1443) } \\
\text { (Peláez Benítez } \\
\text { 1999: 145) }\end{array}$ \\
\hline $\begin{array}{l}\text { Als quals Jàson e } \\
\text { Hèrcules no fo } \\
\text { denegada, ans bé } \\
\text { promesa e atorgada, } \\
\text { gran ajuda per los } \\
\text { reys e duchs de } \\
\text { Grècia, qui, tots } \\
\text { ensemps e d'un } \\
\text { coratge, loen e } \\
\text { aproven venjança } \\
\text { (pág. 62). [...] Los } \\
\text { quals dos reys frares, } \\
\text { ab molta afecció de } \\
\text { paraules e ab } \\
\text { volentat no fenta, } \\
\text { atorgaren a Hèrcules } \\
\text { agradablement e } \\
\text { d'un coratge ço que } \\
\text { per ell fo demanat. }\end{array}$ & $\begin{array}{l}\text { Más Ércules et Jasón, } \\
\text { non oblidando la } \\
\text { injuria que les fue } \\
\text { fecha por Laomedón, } \\
\text { rey de Troya [...] } \\
\text { Breument, todos de } \\
\text { un coraçón acordaron } \\
\text { de tomar venguança } \\
\text { de las sobredichas } \\
\text { injurias et É<r>cules } \\
\text { tomó en sí toda la } \\
\text { carga del negocio et } \\
\text { de la guerra. }\end{array}$ & $\begin{array}{l}\text { Asi que les fallesçieron } \\
\text { muchos rreyes e } \\
\text { duques que a Jason e } \\
\text { Hercoles prometieron } \\
\text { ser con ellos en la tal } \\
\text { vengança de la jnjuria } \\
\text { fecha por el rrey } \\
\text { troyano. [...] Al qual } \\
\text { Hercoles estos rreyes } \\
\text { rrespondieron } \\
\text { ofresçiendosele con } \\
\text { mucha afecçion e } \\
\text { voluntad non jnfjntosa } \\
\text { de ser con el en vn } \\
\text { querer çerca de } \\
\text { aqueste fecho. }\end{array}$ & $\begin{array}{l}\text { Fueles para } \\
\text { conplimento de tanto } \\
\text { negocio demandada } \\
\text { ayuda a cada uno, } \\
\text { segunt su facultad, e } \\
\text { para la vengança } \\
\text { fazedera contra el rey } \\
\text { Laumedonta, } \\
\text { reprovada por los } \\
\text { reyes e duques de los } \\
\text { griegos, por } \\
\text { hordenada promesa } \\
\text { les fue otorgada } \\
\text { ayuda [...] Los cuales } \\
\text { reyes con muncha } \\
\text { afección de palavbras } \\
\text { e voluntad non } \\
\text { fengida a Ércoles de } \\
\text { una voluntad } \\
\text { ofresciendo sin pereça } \\
\text { otorgaron. }\end{array}$ \\
\hline
\end{tabular}

Las versiones peninsulares derivadas de la $H D T$ resuelven de forma variada la traducción del adverbio latino vnanimiter. En el caso de la vulgarización del primer contexto, se observa que las versiones castellanas emplean paráfrasis muy indirectas para traducirlo. Así, tanto La corónica troyana como el Libro de la historia troyana resuelven esta traducción por medio de las construcciones sintácticas regulares ser con ellos y por hordenada promesa, respectivamente, que no reflejan propiamente el significado del adverbio latino, sino que lo parafrasean de forma muy indirecta. Por su parte, la versión catalana resuelve la traducción con la combinación tots ensemps e d'un coratge ${ }^{20}$, mientras que la aragonesa, en razón de su esquematismo narrativo, tan solo traduce este adverbio en una sola ocasión con la unidad todos de un coraçón. Como puede apreciarse, estos dos últimos resultados de vulgarización se aproximan mucho más a la secuencia registrada en el texto de Los doze trabajos de Hércules.

En el caso del segundo contexto, en todas ellas se ofrecen resultados de traducción en forma de combinaciones locucionales muy próximas también a la secuencia empleada por Villena, con la excepción de la versión castellana incompleta, en la que se utiliza la unidad en vn querer ${ }^{21}$. Con 
todo, si bien resulta parcialmente divergente con respecto a las anteriores, hay que destacar en todo caso la afinidad semántica contextual entre las voces voluntad, coraçón, coratge ${ }^{22}$ y querer, con el matiz común de 'disposición anímica unánime para emprender alguna acción'.

El estudio diacrónico de las secuencias conformadas en torno a diferentes núcleos léxicos semánticamente afines como compañía, coraçon, querer o voluntat nos ha permitido comprobar su historicidad profunda en el desarrollo de los diferentes romances hispánicos a través del proceso de conformación y aclimatación de los modelos prosísticos heredados. Ello nos muestra que, en el momento en que la materia de Troya se vulgariza en castellano, catalán y aragonés a partir del texto latino de Guido delle Colonne desde el último cuarto del siglo XIV, estas combinaciones fraseológicas ya se habían infiltrado de forma uniforme y progresiva en el discurso prosístico de signo historiográfico de los espacios culturales peninsulares mencionados, como se ha tenido ocasión de comprobar con la exposición de los datos contextuales de la General Estoria, de la Grant Crónica de Espanya o de la Crònica de Pedro IV de Aragón.

Ello presenta, naturalmente, unas implicaciones de enfoque a la hora de enmarcar y valorar la continuidad estilística de estas secuencias locucionales en Los doze trabajos de Hércules de Enrique de Villena, pues, a diferencia de la unidad fraseológica que se estudiará a continuación, las secuencias locucionales descritas en este apartado presentan una consolidación firme en el discurso prosístico de los diferentes romances hispánicos, por lo que atribuir el uso de estas combinaciones en el texto que nos ocupa a esa posible influencia de la tradición narrativa de materia troyana supondría obviar el recorrido diacrónico que estas unidades dibujan desde la segunda mitad del siglo XIII a través de la documentación castellana, catalana y aragonesa.

\subsection{Con mano fuerte y sus variantes fraseológicas}

En el marco del tercer trabajo, en el que Hércules aleja a las arpías del rey Fineo en razón de su influencia perjudicial para con sus hijos, Villena emplea la combinación locucional adverbial con mano de fortaleza para referirse a la actitud moral firme y perseverante de la persona virtuosa a la hora de controlar sus pasiones:

Aquesta ficçión en parte es parabólica e en parte fabulosa, significando por Fineo el estado del omne virtuoso, que deve seer rey de las sus passiones, rigiéndolas con mano de fortaleza e constançia moral. Aqueste tal conviene seer junto en matrimonio con la derecha entinçión e sana (Cátedra 2007: 30).

En otro pasaje del texto, concretamente en el desarrollo narrativo del sexto trabajo, en el que Hércules castiga la crueldad del rey Diomedes matándolo y entregando su cuerpo a los caballos como comida, Villena emplea también otra combinación fraseológica muy cercana a la anterior, con mano poderosa, con el fin de hacer referencia al modo guerrero con que afronta Hércules su misión en el reino de Tracia:

Non osavan dezir en público sus quexas nin morar en el regno e menos salir d'él por la muchedumbre de las gentes que aquella diabólica más que humana fazían execuçión. El rumor e fama llegó a los fines de la tierra. D’esto sabidor Ércules, fue al regno de Trasçia con mano poderosa e subjudgó el rey Diomedes a sí (Cátedra 2007: 47).

Finalmente, en el décimo trabajo, en el que se cuenta la historia mitológica del robo del ganado de Hércules por parte de Caco, Villena emplea la combinación locucional de tipo adverbial con 
mano fuerte, con el fin de expresar la superioridad del héroe aqueo en su batalla contra el rey Gerión, que resulta el personaje supuestamente real que se esconde tras la fábula:

E tanta era la concordia e amistad entr'ellos, aviendo una voluntad, que fingieron que non era más de un Girión. E siquiere fuese uno, siquiere muchos, así como uno Hércules reduxo con mano fuerte a bien señorear e quitó los tuertos que por Girión antes en España eran fechos sin contradizimiento o detenimiento (Cátedra 2007: 68).

Para la secuencia locucional con mano de fortaleza, el CORDE registra tan solo el pasaje de nuestra obra, por lo que, si bien parece aventurado apresurarnos a afirmar que se trata de una innovación estilística de cuño personal, lo cierto es que resulta un segmento que, a la luz del banco de datos de la Real Academia Española, podría catalogarse como un hápax fraseológico.

En cambio, para la combinación con mano poderosa, el coRDE registra hasta 47 casos. El primer registro que ofrece esta base de datos se corresponde con la Traducción de la "Historia de Jerusalem abreviada", de Jacobo de Vitriaco, fechado con posterioridad a 1350. Con todo, hay que tener en cuenta que el testimonio manuscrito en que se recoge este texto está datado entre 1401 y 1450 , por lo que cabe la posibilidad de que el copista haya trasladado una parte de sus usos lingüísticos al texto original (Fernández-Ordóñez 2006). Los dos casos siguientes se registran en la obra herediana Obra sacada de las crónicas de San Isidoro, de Lucas de Tuy, fechada entre 1385 y 1396 : "por las quales ujctorjas e prosperidades Muza se leuanto contra el rey Ordonjo con mano poderosa, e el rey Ordonjo moujo la su huest e fue a la ciudat [...]". Además de otros testimonios en que se registra dicha unidad, como en la Biblia escurialense I-j-4 (c. 1400) o en una colección anónima de sermonarios fechada de forma genérica en la primera mitad del siglo XV, hay que destacar que Villena utiliza esta combinación fraseológica en otras de sus obras literarias, como en el Tratado de consolación (1424) y en la Traducción y glosas de la Eneida. Libros I-III (1427-1428), que resultan, en todo caso, de creación posterior a Los doze trabajos de Hércules.

Finalmente, abordaremos el estudio de la trayectoria histórica de la unidad con mano fuerte. La primera búsqueda que se ha realizado en CORDE ha sido la de la secuencia locucional con mano fuert, que se registra en cinco casos. Los tres primeros se localizan en La fazienda de Ultramar (c. 1220) que, pese a considerarse "la primera obra extensa en prosa castellana", presenta numerosos elementos procedentes de romances del Oriente peninsular "atribuibles a traducción chapucera de un original gascón, o a intervención de un traductor gascón o catalán” (Lapesa 1981: 233-234), con una especial incidencia de la apócope extrema en el texto, como parece ser el caso de fuert en el marco de la secuencia analizada 23.

Por su parte, la secuencia con mano fuerte se registra en CORDE en 114 casos. De nuevo, la primera mención que ofrece este banco de datos es la Traducción de la "Historia de Jerusalem abreviada", de Jacobo Vitriaco. El siguiente dato en que se documenta, correspondiente a la obra Barlaam e Josafat, presenta también divergencias destacadas en lo que concierne a su fecha de composición y a la de las fuentes conservadas ${ }^{24}$. Siguiendo la línea cronológica del CORDE, los cuatro datos contextuales siguientes se registran en la Biblia de El Escorial I-j-4, fechada en torno a 1400. Otros cuatro datos contextuales que siguen antes de llegar a la mención de Los doze trabajos de Hércules se corresponden con la Biblia ladinada I-j-3, fechada en torno a 1400, si bien la copia manuscrita en que se conserva está datada entre 1426 y 1450.

Sea como sea, analizados, pues, los textos anteriores a la obra de Villena, resulta destacable que esta combinación presenta un uso relativamente escaso en el conjunto de la documentación 
medieval castellana en el contexto próximo de creación a Los doze trabajos de Hércules. La percepción de ese uso escaso se afianza al comprobar que, tras la mención de la obra que nos ocupa, compuesta en 1417, no se vuelve a registrar esta secuencia locucional hasta mediados del siglo XVI, esta vez ya de forma continuada e ininterrumpida.

Los datos que nos ofrece la tradición lexicográfica también discurren parejos al trazado cronológico descrito anteriormente. En este sentido, la primera referencia directa se localiza en la edición de 1803 del diccionario académico (s.v. mano), fecha muy tardía con respecto a su aparición en los textos y bajo la forma de una locución nominal - mano fuerte-, definida en estos términos: "En lo forense la gente armada para hacer cumplir lo que el juez manda, y tambien la que el juez secular manda dar al eclesiástico quando este implora su auxilio". Sorprende, pues, su ausencia de codificación en la tradición lexicográfica del español si se tiene en cuenta que se registra de forma ininterrumpida en los textos literarios en lengua castellana.

En el espacio aragonés y, concretamente, en la obra de Juan Fernández de Heredia, se registran algunas secuencias estrechamente relacionadas con las descritas hasta ahora. Así, en la primera parte de la Grant Crónica de Espanya (GCE I), terminada en 1385, si bien no se documenta la combinación locucional con mano poderosa, sí que coaparecen los componentes léxicos mano y poderosament, lo cual resulta importante anotar, pues nos marca con toda seguridad una primera fase en su proceso de lexicalización: "\& entre ellos no era ningun dubdo que aquel no le tallas la cabeça en j golpe \& como el leuantase la mano poderosament por darle el capellan sanctulo qui auia muyt grant deuoçion en sant iohan baptista [...]" (fol. 547). En esta misma obra, así como en la Obra sacada de las crónicas de san Isidoro, también se registra la secuencia en mano fuert: "Aquesti prologo he deuant posado porque en la primera fuent del uolumpne aprengant los principes por claro negoçio dalto linatge gouernar no menos sauiament \& piadosa que en mano fuert los regnos a ellos diusmetidos" (GCE I, fol. 386).

El CICA registra desde la segunda mitad del siglo XIV el uso de la combinación locucional $a b$ mà poderosa, que resulta paralela a la combinación documentada en la obra de Villena: “[...] si no, que lo y manàs, car de continent lo governador hi seria ab mà poderosa per fer-lo n'exir" (Epistolari de la València medieval). El Diccionari català-valencià-balear (s.v. mà) registra otro dato contextual de la combinación adverbial $a b$ mà fort, si bien en su forma citativa se codifica bajo el sintagma lluitar amb mà forta, y se define como 'lluitar vigorosament'. Lo relevante del testimonio es que se corresponde, precisamente, con la Vita Christi de sor Isabel de Villena, hija de Enrique de Villena: "qui $a b$ mà fort pugnarà per nosaltres"25.

A pesar de que no se dé una correspondencia formal idéntica entre todas las combinaciones consideradas, no será necesario insistir en la filiación genética que se da entre las secuencias con mano de fortaleza, con mano poderosa y con mano fuert(e), amén de las representadas en la documentación aragonesa y catalana en mano fuert, ab mà poderosa y ab mà fort, con respecto al sintagma lexicalizado IN POTENTI MANU, registrado en la Historia destructionis Troiae de Guido delle Colonne, con un significado común en todos ellos de 'con gran potencia física': "Nichil enim aliud et ita peragere quam ei competencia indulgere spacia libertatis vt per eum quesita presidia cumulet et sibi cotidie multa subsidia coaceruet, cum tanti temporis sint iam exacta curricula quod in potenti manu debueritis iam inuadere regnum eius" (Griffin 1936: 99).

Pues bien, al igual que en el caso anterior, también en las versiones peninsulares de materia troyana derivadas de la Historia destructionis Troiae se registran combinaciones locucionales adverbiales estrechamente emparentadas con las registradas en el texto de Villena, con lo que la 
idea de continuidad estilística entre nuestro texto y el haz de versiones peninsulares reunidas en torno a la guerra de Troya resulta una hipótesis asumible.

Así, al final del libro VII, en el pasaje relativo a la unión matrimonial entre Paris y Helena, Casandra, la hija de Príamo y de Hécuba, reacciona ante tal acontecimiento con lamentos y profecías sobre la inminente destrucción de Troya por esta injuria hacia Grecia, e implora que Helena sea restituida al pueblo griego separándola de forma contundente de su reciente marido Paris. Y ese matiz de contundencia evocado se expresa en la obra historiográfica latina mediante el sintagma lexicalizado in uiolenta manu, resuelto en las versiones peninsulares de materia troyana de diversa manera:

Ha misera Heccuba, vnde tot poteris educere lacrimas in natorum tuorum excidio, quos secabit et incidet cruentatus gladius impiorum? Ha gens ceca et dire mortis ignara, cur in uiolenta manu ab iniusto viro non euellitis Helenam, et eam non acceleratis restitui iusto viro antequam durus ensis acceleret et gladius acutus vestro deferueat in cruore? (Historia destructionis Troiae [c. 1287], Griffin 1936: 79).

Tabla 2. Combinaciones fraseológicas referidas a la profecía de Casandra

\begin{tabular}{|c|c|c|c|}
\hline \multicolumn{4}{|c|}{ Combinaciones fraseológicas referidas a la profecía de Casandra } \\
\hline $\begin{array}{l}\text { Històries troianes } \\
\text { (1367-1374) } \\
\text { (Perujo Melgar } \\
\text { 2015: 130) }\end{array}$ & $\begin{array}{c}\text { Crónica troyana } \\
(1385-1396) \\
\text { (Sanz Julián 2012: 66) }\end{array}$ & $\begin{array}{l}\text { La corónica troyana } \\
\text { (c. 1400) } \\
\text { (Pelletier Norris } \\
\text { 1970: 121). }\end{array}$ & $\begin{array}{c}\text { Libro de la historia } \\
\text { troyana (1443) } \\
\text { (Peláez Benítez 1999: } \\
\text { 189-190) }\end{array}$ \\
\hline $\begin{array}{l}\text { A, masquina } \\
\text { Héccuba, mare mia, } \\
\text { regina molt noble! } \\
\text { ¿D’on poràs tu tantes } \\
\text { làgremes gitar en la } \\
\text { destrucció de tos fills, } \\
\text { los quals segarà e } \\
\text { taylarà lo coltell cruel } \\
\text { dels malvats? A, gent } \\
\text { cega e no conaxent la } \\
\text { mort cruel qui us ha a } \\
\text { venir! Per què ab mà } \\
\text { poderosa no tollets } \\
\text { Helena al seu marit } \\
\text { injust, e que sia } \\
\text { restituïda al seu marit } \\
\text { just, ans que·l coltell } \\
\text { cruel se encruelescha } \\
\text { en la vostra sanch e } \\
\text { dels vostres? }\end{array}$ & $\begin{array}{l}\text { ¡Hay, miserable } \\
\text { Éncuba! ¿Et de dónde } \\
\text { podrás sacar tantas } \\
\text { lágrimas en la muert } \\
\text { de los tus fillos, a los } \\
\text { quales despedaçará el } \\
\text { sangriento guchiello } \\
\text { de los crueles? ¡Hay, } \\
\text { gent ciega et ignorant } \\
\text { de la cruel muert! ¿por } \\
\text { qué non arrebatades \& } \\
\text { quitades forçadament } \\
\text { et con mano violenta a } \\
\text { Elena del poderío de } \\
\text { aquel injusto marido et } \\
\text { non vos aquexades de } \\
\text { la restituyr a su justo } \\
\text { marido antes que la } \\
\text { dura spada se aquexe } \\
\text { et el agudo guchillo } \\
\text { fierva en sangre? }\end{array}$ & $\begin{array}{l}\text { ¡O mal afortunada } \\
\text { Ecuba! E commo non } \\
\text { podra de ti manar } \\
\text { tantas lagrimas que } \\
\text { puedas abastar a llorar } \\
\text { la cruel muerte de } \\
\text { todos tus fijos quando } \\
\text { los veras todos } \\
\text { padesçer por cruel } \\
\text { espada. ¡O gente } \\
\text { ciega, que non vedes } \\
\text { njn conosçedes la } \\
\text { cruel muerte que vos } \\
\text { es por venjr! ¿Por que } \\
\text { non fazedes por } \\
\text { qualquier via que sea, } \\
\text { o siquiera por fuerça, } \\
\text { que Helena sea } \\
\text { quitada e partida de } \\
\text { Paris su non deujdo e } \\
\text { jnjusto marido? }\end{array}$ & $\begin{array}{l}\text { ¡O mesquina Écuba! } \\
\text { ¿dónde podrás tantas } \\
\text { lágrimas a tus ojos } \\
\text { traer para lorar la } \\
\text { destruición de tus } \\
\text { fijos, los cuales el } \\
\text { cuchillo } \\
\text { ensangrentado de los } \\
\text { sin piedat matará? ¡O } \\
\text { gente ciega e de la } \\
\text { cruel muerte non } \\
\text { sabidora!, ¿por qué con } \\
\text { mano violenta non } \\
\text { quitáis a Elena del } \\
\text { injusto marido e al } \\
\text { justo con acucia de la } \\
\text { restituir trabajáis, ante } \\
\text { que la cruel espada se } \\
\text { acerque e el agudo } \\
\text { cuchillo en vuestra } \\
\text { sangre fiera? }\end{array}$ \\
\hline
\end{tabular}


A excepción de La corónica troyana, que se aleja de la convergencia formal con el uso de una unidad fraseológica sinónima como lo es por fuerça, el resto de traducciones sigue muy de cerca la secuencia latina con resultados como ab mà poderosa, en el caso de las Històries troianes, y con la combinación con mano violenta, que emplean de forma idéntica tanto la Crónica troyana herediana ${ }^{26}$ como el Libro de la historia troyana.

El hecho de que nuestro autor utilice estas expresiones tan próximas al modelo latino nos ha de hacer pensar en la posibilidad de que Villena estuviera lo suficientemente familiarizado, bien con el original latino, bien con alguna de sus versiones peninsulares, como para haber integrado en su estilo este tipo de combinaciones. Se puede conjeturar, pues, que Villena pudo haber absorbido desde el punto de vista estilístico algunos de los modos de expresión fraseológica representados en esta cadena de textos.

Esta afirmación, que no deja de irradiar cierto riesgo y atrevimiento interpretativos, se refuerza, a nuestro modo de ver, con los datos cronológicos procedentes de los romances hispánicos considerados. Si en el caso de la secuencia locucional en una compañía e de un coraçón tanto la documentación castellana, catalana y aragonesa mostraban que esta unidad presentaba una clara consolidación en el uso desde la segunda mitad del siglo XIII, y ello nos obligaba necesariamente a relativizar la posible intermediación de otras tradiciones literarias y, específicamente, de la tradición narrativa de materia troyana de ámbito hispánico, en el caso de la combinación locucional con mano fuerte, así como de sus variantes fraseológicas con mano de fortaleza y con mano poderosa, esa línea cronológica es inexistente, ni en términos de historicidad ni en términos de frecuencia de aparición. Aun con todo, es necesario matizar que se trata de una hipótesis abierta.

\subsection{A consejo e induzimiento de y sus variantes fraseológicas}

En el marco del tercer trabajo, en el que Hércules aleja a las arpías del rey Fineo en razón de su influencia perjudicial para con sus hijos, Villena emplea el complejo prepositivo a consejo $e$ induzimiento de para referirse a la actitud manipulativa de la madrastra a la hora de influir en la decisión del rey Fineo de dejar a sus hijos sin la administración de los bienes:

Veyendo que los fijos contra consejo e voluntad de la madrastra usavan de franqueza e fazían despender a su padre magníficamente, segúnt al su real estado convenía, e por esto, a consejo e induzimiento de la dicha madrastra, el rey Fineo quitó la administraçión de los bienes a los dichos sus fijos (Cátedra 2007: 31).

Para empezar con la descripción de la trayectoria histórica de esta combinación locucional, hay que afirmar que la secuencia prepositiva a consejo e induzimiento de no se registra en el CORDE27, por lo que, al igual que en el caso de la unidad con mano de fortaleza, se podría conjeturar que estamos ante otro hápax fraseológico. Sin embargo, como nos mostrará la documentación aragonesa, esta aseveración resulta apresurada.

El primer dato contextual que ofrece el CORDE para la voz induzimiento es un fragmento del Libro del cavallero Zifar (c. 1300-1305): "según parece a todos los hombres que, por consejo \& por induzimiento de malos consejeros, que pensaron aver gran parte de lo que el emperador sacasse de sus tierras". Como puede apreciarse, la voz se integra en una secuencia prepositiva prácticamente idéntica a la registrada en el texto de Villena. Con todo, no podemos dar este dato por cierto como realización posible en la lengua de principios del siglo XIV sin antes atender a las cuestiones de historia textual que esta obra medieval encierra. 
De acuerdo con Lucía Megías (2002: 774), el Libro del cavallero Zifar se ha conservado en dos fuentes manuscritas y en una fuente impresa. Tal como destaca este investigador, "los dos manuscritos, así como la edición de 1512 - que tiene como modelo un manuscrito diferente, como lo demuestran diversas omisiones textuales de $M P$ que no se documentan en $S$-, presentan un texto deturpado por la transmisión". Aparte de este carácter deturpado, hay que tener presente que el testimonio manuscrito $M$-ms. 11.309 (olim Ii-87) de la Biblioteca Nacional de Madrid-se copió a principios del siglo $\mathrm{xV}$, mientras que el testimonio $P-$ ms. Esp. 36 de la Bibliothèque Nationale de France- se conformó en la corte de Enrique IV hacia el último tercio del siglo $\mathrm{XV}^{28}$. El texto impreso, por su parte, data del 9 de junio de 1512 (Sevilla, Jacobo Cromberger) ${ }^{29}$. Todo ello nos debe hacer considerar la posibilidad de que alguno de los copistas del texto modernizara la lengua con la inclusión de la voz induzimiento en el marco de una estructura gramatical altamente representativa de la lengua literaria cuatrocentista: la secuencia bimembre formada por dos voces semánticamente afines, como es el caso de la unidad estudiada a consejo e induzimiento de.

El segundo dato contextual, correspondiente a una carta del rey Jaime II dirigida a doña María de Molina, datado en 1319, ya nos señala un camino seguro de interpretación filológica, pues en dicha carta, emanada desde el marco institucional y administrativo de la Cancillería de la Corona de Aragón, se dejan ver algunos rasgos aragoneses en voces como fruyto, eglesia, aquesto, faulamos o sagrament. Junto a estas formas se registra también la voz induzimiento: "rezelando nos ya de aquesto e alli havia muchas buenas razones de induzimiento de complir su matrimonio e finalmente otorgo nos qve faria su matrimonio e sollepnisaria en la Iglesia por conplir el nuestro sagrament e homenage [...]".

Precisamente, el tercer y cuarto pasaje se corresponde con la obra literaria de Juan Fernández de Heredia. El tercero se registra en la traducción aragonesa de la Historia adversus paganos, de Paulo Orosio, datada entre los años 1376-1396: “Onde a los cartaginés pareció vn tiempo seyer bueno sacrificar hombres, el qual induzimiento et consello assi mal presumido en breve fue dexado" (Romero Cambrón y García Pinilla 2008: 336) ${ }^{30}$. Lo relevante de este dato contextual, aparte de su adscripción al espacio cultural aragonés, es que en él se registran ambas voces en solidaridad léxica, lo que tendrá continuidad un tiempo después en la obra de Villena.

El cuarto pasaje, registrado en la Primera Partida de la Grant Crónica de Espanya (ms. 10.133 de la Biblioteca Nacional de Madrid, fol. 371v), presenta como nota característica el hecho recurrente de que esta voz se documente en su uso contextual en el marco de una secuencia prepositiva:

\& encontinent refuso \& echo de si octauia su muger hermana qui era de octauiano çesar augusto emperador de ponient $\&$ enuio por cleopatra reyna de egipto \& prisola por muller. \& tanto por su ergull \& uoluntat quende auie / \& tanto por induzimiento de clepatra que deseaua regnar \& senyorear en roma [...]

Más allá de estos dos contextos significativos para el estudio de la aclimatación de la combinación locucional a consejo e induzimiento de en Los doze trabajos de Hércules, su uso se documenta en la traducción de las Décadas de Tito Livio, realizada por el canciller Pero López de Ayala, en el Libro de los exemplos por A.B.C, así como en los Proverbios de Íñigo López de Mendoza (marqués de Santillana). 
Tabla 3. Representatividad de las combinaciones prepositivas con núcleo inducimiento

\begin{tabular}{|c|c|}
\hline Combinaciones prepositivas & Documentación en el Corpus diacrónico del español \\
\hline \multicolumn{2}{|r|}{ INDUZIMIENTO } \\
\hline a induzimiento de & $\begin{array}{l}\text { "a induzimiento de aquellos vellacos" (Segunda parte de la Crónica } \\
\text { general de las Indias, de Francisco López de Gómara, 1553). }\end{array}$ \\
\hline de induzimiento de & $\begin{array}{l}\text { “de induzimiento de complir su matrimonio" (Anónimo, Carta de } \\
\text { Jaime II a doña María de Molina, 1319). }\end{array}$ \\
\hline por induzimiento de & $\begin{array}{l}7 \text { casos, localizados a lo largo del siglo XV, además de su primera } \\
\text { mención, correspondiente al Libro del cavallero Zifar ("por } \\
\text { induzimiento de malos consejeros"). }\end{array}$ \\
\hline \multicolumn{2}{|r|}{ INDUÇIMIENTO } \\
\hline a induçimiento de & Sin casos \\
\hline en induçimiento de & Sin casos \\
\hline por induçimiento de & “por induçimiento de Pero Niño” (Anónimo, Carta de Juan II, 1426). \\
\hline \multicolumn{2}{|r|}{ INDUSCIMIENTO } \\
\hline a induscimiento de & Sin casos \\
\hline en induscimiento de & Sin casos \\
\hline por induscimiento de & Sin casos \\
\hline \multicolumn{2}{|r|}{ INDUSÇIMIENTO } \\
\hline a indusçimiento de & Sin casos \\
\hline en indusçimiento de & Sin casos \\
\hline por indusçimiento de & Sin casos \\
\hline \multicolumn{2}{|r|}{ INDUCIMIENTO } \\
\hline a inducimiento de & $\begin{array}{l}\text { "a inducimiento de malas personas" (Jerónimo Zurita, Anales de la } \\
\text { Corona de Aragón. Segunda parte, 1579). }\end{array}$ \\
\hline en inducimiento de & Sin casos \\
\hline por inducimiento de & $\begin{array}{l}32 \text { casos, localizados todos ellos desde el primer tercio del siglo XVI } \\
\text { hasta el primer tercio del XVII. }\end{array}$ \\
\hline
\end{tabular}

Para tratar de completar el recorrido de esta voz, será oportuno recoger la información que nos ofrece la tradición lexicográfica en términos de codificación. De acuerdo con el Nuevo tesoro lexicográfico de la lengua española (NTLLE), el primer diccionario que recoge esta voz es el Vocabulario (¿1495?) de Nebrija31, y en él se codifican hasta tres entradas relacionadas. Interesa destacar en este sentido que la entrada tercera ofrece como equivalente el sustantivo latino exhortatio. Aparte de este lema, codifica también la forma verbal induzir, así como el derivado deverbal induzidor. En la línea de los diccionarios multilingües de los siglos XVI y XVII, César Oudin incorpora por primera vez la entrada inducción bajo las variantes induction e inducion en su Tesoro de las dos lenguas francesa y española (1607). A partir del registro de la voz inducción en el diccionario de Oudin, junto con el conjunto de voces en torno a la forma verbal induzir (induzido, induzidor e induzimiento), el resto de diccionarios que conforman la tradición lexicográfica moderna y contemporánea incluirá en sus respectivas nomenclaturas las voces descritas, hasta el punto de que la voz inducimiento aparece codificada en la última edición del Diccionario de la lengua española (2014), si bien bajo la marca desusado.

Tras haber comprobado la codificación lexicográfica de la voz induzimiento y su forma sinónima inducción ${ }^{32}$, regresemos ahora al estudio de la documentación histórica, con el fin de esbozar la trayectoria histórica de la voz inducción, así como de su correspondiente reflejo en catalán bajo la forma <inducció > y en aragonés <induction> e <induçion>. 
La forma <inducçión> se registra en seis ocasiones en el Corpus diacrónico del español. Precisamente, de ese total de seis casos, los tres primeros se documentan en obras de Enrique de Villena, por lo que, de acuerdo con el banco de datos de la Real Academia Española, esta voz aparece por primera vez en la documentación escrita en lengua castellana en el Arte cisoria (1423) de nuestro autor. Como se aprecia, la voz considerada, en su condición de voz nuclear junto a conservaçión, se integra en una combinación prepositiva, conformada mediante una estructura gramatical compleja:

E por eso, pues era la mundial e sensible máchina començada e nueva, convernía los usos mundanos oviesen comienço por los omnes razonables, capaçes de fallar las cosas a ellos nesçesarias, convenibles e buenas, $a$ conservaçión e inducçión de virtuosa vida, que los apartase de la sensualidat e bestial partiçipio.

A este primer registro le siguen dos datos pertenecientes a la Traducción y glosas de la Eneida (1427-1428), si bien no presentan naturaleza fraseológica. También en los Trabajos se registra una secuencia prepositiva similar a la registrada en la traducción castellana de la Eneida como es $a$ conservaçión e defendimiento de: "Por estado de cavallero entiendo rico omne, noble, [...] a quien pertenesçe usar, exerçer e multiplicar las costumbres virtuosas e buenas, a conservaçión $e$ defendimiento del bien común" (Cátedra 2007: 18).

De hecho, desde el punto de vista de su valor semántico contextual, ambas parecen generar significados relacionados con los principios de la filosofía moral y de otros ámbitos de conocimiento afines, como la lógica o la retórica. A este respecto, parece que la acepción siguiente, apresada en el Diccionario de autoridades (DA s.v. inducción) ${ }^{33}$, sería la más próxima al contexto semántico de los pasajes estudiados hasta ahora, en los que no se descarta que la secuencia locucional utilizada por Villena presente un carácter técnico, ligado a la prosa de la Cancillería aragonesa:

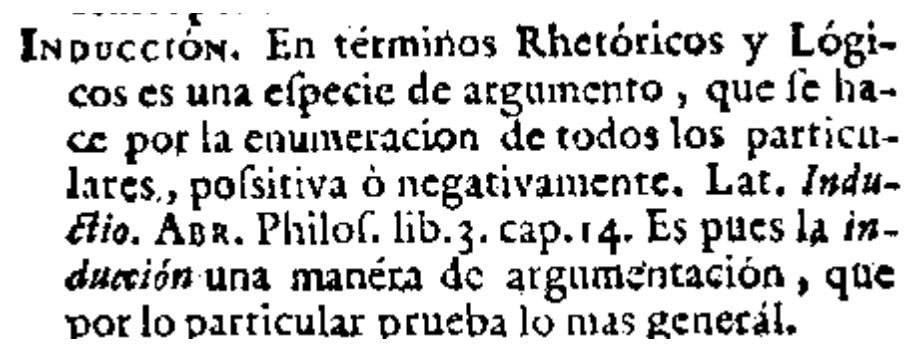

Los tres restantes casos corresponden a las obras anónimas Traducción del Libro de las donas, de Francesc Eiximenis (c. 1448) y a las Etimologías romanceadas de San Isidoro (c. 1450). Por su parte, la forma inducción, en su condición de forma lingüística del español actual en su aspecto gráfico, se registra en un total de 422 casos de forma ininterrumpida desde mediados del siglo XVI hasta nuestros días. 
Tabla 4. Representatividad de las combinaciones prepositivas con núcleo inducción

\begin{tabular}{|c|c|}
\hline Combinaciones prepositivas & Documentación en el Corpus diacrónico del español \\
\hline \multicolumn{2}{|r|}{ INDUÇIÓN } \\
\hline a induçión de & Sin casos \\
\hline de induçión de & Sin casos \\
\hline por induçión de & Sin casos \\
\hline \multicolumn{2}{|r|}{ INDUCIÓN } \\
\hline a indución de & Sin casos \\
\hline en indución de & Sin casos \\
\hline por indución de & $\begin{array}{l}\text { "por indución de los seglares" (Fray Bartolomé de las Casas, Historia } \\
\text { de las Indias, c. 1527-1561). }\end{array}$ \\
\hline \multicolumn{2}{|r|}{ INDUCÇIÓN } \\
\hline a inducçión de & Sin casos \\
\hline en inducçión de & Sin casos \\
\hline por inducçión de & Sin casos \\
\hline \multicolumn{2}{|r|}{ INDUCCIÓN } \\
\hline a inducción de & $\begin{array}{l}\text { "a induccion de algunos del conseio" (Anónimo, Documento } \\
\text { [Documentos judíos],1321) }\end{array}$ \\
\hline en inducción de & Sin casos \\
\hline por inducción de & $\begin{array}{l}3 \text { casos, cuya primera mención se localiza en el documento Don } \\
\text { Fernando al cardenal de Santa Cruz, 1496: "por inducción de } \\
\text { Lobera". El resto de casos se registra en } 1769 \text { y } 1876 \text {. }\end{array}$ \\
\hline \multicolumn{2}{|r|}{ INDUCTION } \\
\hline a induction de & $\begin{array}{l}\text { "ni a induction de su madre" (Anónimo, De las mujeres ilustres en } \\
\text { romance, 1494). }\end{array}$ \\
\hline en induction de & Sin casos \\
\hline por induction de & Sin casos \\
\hline \multicolumn{2}{|r|}{ INDUZION } \\
\hline a induzion de & Sin casos \\
\hline en induzion de & Sin casos \\
\hline por induzion de & Sin casos \\
\hline
\end{tabular}

Con relación a la trayectoria histórica de la voz catalana inducció, el Corpus Informatitzat del Català Antic (CICA) registra la voz inducció desde la primera mitad del siglo XIV en la documentación administrativa de la Cancillería aragonesa. Lo que resulta realmente significativo para nuestro análisis es la recurrencia con que esta voz se integra, como en el caso de la documentación castellana, en una combinación prepositiva. Así, la mayor parte de los datos contextuales, fechados a lo largo de los siglos XIV y XV, reproduce la secuencia a inducció de, per inducció de o, de forma testimonial, ab inducció de. Parece como si el origen de esta voz, acreditado desde las primeras décadas del siglo XIV, estuviese ligado necesariamente a su uso contextual en un segmento locucional de tipo prepositivo.

Si bien el banco de datos CICA no registra ningún caso referido a la forma induïment, la lexicografía histórica catalana sí que da cuenta de la existencia de esta voz en la documentación textual. El Diccionari català-valencià-balear la codifica bajo la marcación "antigua", y la hace remitir a 'inducció'. Ofrece como testimonio único un documento anterior a 1404, en el que se puede leer: "sense induhiment ne consell d'altre alcú". Como en el fragmento de las Historias contra los paganos, también aquí coaparecen ambas voces, lo que supone un principio incipiente de fijación. También 
el Diccionari etimològic i complementari de la llengua catalana recoge esta voz y la describe en estos términos "de l'antic continuador de INDUCERE" (1980-2001: III, 220). Asimismo, incluye las variantes, marcadas como antiguas, enduement y endusament, documentadas en las Vides de sants rossellonesos (c. 1260).

Tal como se ha visto anteriormente en relación con la presencia de la voz induzimiento en la obra de Juan Fernández de Heredia, también para el caso de la voz sinónima inducción se registran datos contextuales bajo las formas gráficas <induction>, <induccion>, <inducion> e <induçion>, documentadas tanto en la primera partida de la Grant Crónica de Espanya como en la segunda parte de la Grant Crónica de los Conquiridores.

Así, la forma <induçion> se registra en una sola ocasión en la primera partida de la Grant Crónica de Espanya (fol. 433r) en el marco de una combinación prepositiva de estructura compleja: "\& fuyo atalarico la ora fridigerno queriendo render graçias al emperador porel benefiçio a el fecho demando paç perpetua del \& el emperador ualent a suasión \& induçion del maluado Euduxio [...]". El hecho de que la voz suasión se acompañe de la voz sinónima induçion nos podría indicar dos hechos complementarios: por un lado, se podría pensar que la voz suasión, en su condición de voz culta, resultaría en la época lo suficientemente opaca desde el punto de vista semántico como para reforzar su procesamiento con la voz sinónima induçion. Por otro lado, como consecuencia directa de tal hipótesis, habría que presuponer que esta última voz tendría ya una circulación consolidada en los ámbitos cultos de la producción literaria en aragonés. Esta hipótesis parece confirmarse si nos atenemos al pasaje de la Grant Crónica de los Conquiridores (fol. 165v), que evoca el mismo contenido que el magnum opus herediano: "por que segunt dicho es de part de suso los godos fueron decebidos en tiempo de valient emperador erege por auulsilla lur bispe a inducio e frau de eudoxio".

Aparte de estos dos datos contextuales, en diferentes pasajes de estas compilaciones y de otras traducciones heredianas se registran otras combinaciones locucionales de tipo prepositivo, en las que la voz inducción está presente en las formas gráficas expuestas. Así, en la segunda parte de la Grant Crónica de los Conquiridores se registran secuencias como a inducción de (fol. 183v), a inducción e amonestacion de (fol. 98r) o, bajo la forma <induction>, por induction de (fol. 233r). Precisamente, bajo esta forma gráfica se registra hasta en doce ocasiones en la primera partida de la Grant Crónica de Espanya, y todas ellas integradas en una combinación de tipo prepositivo. Así, muestras fraseológicas como a induction de (fol. 439v), por induction de (fol. 326r) y a induction \& solicitut de (fol. 424v) revelan el proceso de aclimatación ya avanzado en virtud del cual la voz inducción coaparece de forma intermitente con otras voces semánticamente afines ${ }^{35}$.

Si bien en las versiones peninsulares de materia troyana no se registra esta combinación locucional de estructura compleja ${ }^{36}$, resulta importante destacar que en las Històries troianes (1367-1374) de Jaume Conesa se registra la secuencia prepositiva a inducció de, así como su variante per inducció de: "E a inducció de Medea, Jàson aturà en la ylla de Colchos per espay d'un mes" (Perujo Melgar 2015: 61) ${ }^{37}$ y “[...] E manà espressament a Hèctor que aquell dia no entràs en la batayla, de què Hèctor tot se escalfà en ira, e per allò moltes injúries e repreniments dix a sa muller, per inducció de la qual era estat fet que ell no isqués a la batayla" (Perujo Melgar 2015: $242)^{38}$.

La versión castellana realizada por Pedro de Chinchilla en 1443 recurrirá a otros elementos léxicos para resolver dicha traducción: "E a ruego de Medea, Jasón en la isla de Colcas un mes folgó" (Peláez Benítez 1999: 144) y "Por aquel mandamiento Héctor todo en ira encendido, munchas 
injurias e reprehensiones a su muger dixo, porque por su acucia e sujestión sintió ser quello tractado" (Peláez Benítez 1999: 276). Es evidente que las unidades inducció y ruego, representadas en la versión catalana y castellana de la Historia destructionis Troiae, presentan matices contextuales de signicado lo suficientemente alejados como para no ensayar una suerte de oposición estilística entre ambas.

Es importante señalar que en el texto latino no se recoge el sustantivo inductiō, a pesar de que forma parte del vocabulario latino desde época clásica ${ }^{39}$. En su lugar, las unidades léxicas suasum y suggestionem resultan las voces elegidas por Guido delle Colonne en su Historia trojana (c. 1287) para comunicar la actitud persuasiva de Medea: "Sicque ad Medee suasum Iason in Colcos per unius mensis spatium moram traxit" (Griffin 1936: 31) y "Et Hectori mandauit expresse ut eo die se non deberet preliis immiscere. Hector uero totus propterea exarsit ad iram. Propter quod multas iniurias et exprobraciones uxori sue dixit, per quam, ad suggestionem eius, presensit esse tractatum ne ad bellum exiret" (Griffin 1936: 172).

En la tarea compleja por reconstruir las decisiones estilísticas que va adoptando Villena en su autotraducción a la lengua castellana a partir del original catalán, hay que suponer que el escritor traslada el contenido de la obra teniendo ante sí en todo momento la versión primera en aquella lengua. De lo expuesto hasta ahora, se pueden extraer, pues, algunas consideraciones de interés con respecto al empleo de la voz castellana induzimiento por parte de Villena.

En primer lugar, parece evidente que el uso de esta forma habría que circunscribirlo tanto al dominio catalán como al aragonés en virtud de una documentación textual temprana en ambas lenguas con respecto a la documentación castellana. Así, tanto el registro de la combinación prepositiva a induccio de / per inducció de para el dominio catalán desde las primeras décadas del siglo XIV, como la presencia de la voz induzimiento e inducción y de sus correspondientes realizaciones fraseológicas en la obra de Juan Fernández de Heredia dan cuenta del proceso de irradiación léxica desde los espacios culturales mencionados hasta los dominios de la lengua castellana, con lo que la obra de Villena podría concebirse como una estación de intermediación entre ambos dominios lingüísticos.

En segundo lugar, otro rasgo sobresaliente reside en el hecho de que las unidades castellanas y aragonesas <induzimiento>, <inducción>, <induction>, <inducion> o <induçion>, así como las correspondientes catalanas <induhiment> e <inducció>, se integran en la mayor parte de los pasajes comentados en secuencias locucionales de tipo prepositivo. Este hecho presenta una importancia fundamental a la hora de trazar el proceso de germinación y de difusión de este haz léxico, con implicaciones evidentes en el terreno fraseológico.

Finalmente, en la línea de vincular las decisiones estilísticas que adopta Villena en su texto en relación con los índices de estilo presentes en los textos peninsulares de materia troyana, creemos que un elemento de discusión relevante radica en el hecho de que tanto en el pasaje narrativo de la obra de Villena como en los dos fragmentos de las versiones peninsulares de materia troyana consideradas, el agente que cumple la acción de persuadir de forma hábil e inteligente al guerrero aqueo es siempre un personaje femenino. Ello da cuenta, en definitiva, de una singularidad destacable que, si bien no formaría parte de la configuración semántica de esta voz, sí que podría entenderse en términos de una restricción contextual, en el marco amplio de la tradición textual de signo historiográfico. 


\subsection{A pro e acresçentamiento de, por acresçentamiento de y por cresçimiento de, con sus variantes fraseológicas}

En el cuarto trabajo se narra la peripecia de Hércules al enfrentarse al dragón del Jardín de las Hespérides. Este vergel, custodiado por tres doncellas - hijas de Espero- fue construido por el Atalante, rey de Libia. Este monarca ideó este huerto compuesto de árboles de oro con el fin de mostrar su enorme riqueza. En medio de aquel jardín, plantó el árbol más alto, coronado por una manzana de oro, férreamente vigilada por el mencionado dragón. En la secuencia alegórica desarrollada por Villena, el huerto es el conjunto de ciencias ordenadas, que producen frutos de oro y, en su condición de ciencia principal, en medio del jardín se sitúa la filosofía, lo que simboliza que Hércules, a fuerza de estudio, vence la rudeza y consigue encumbrarse a las cotas más altas del saber.

En el marco de la secuencia narrativa correspondiente a la "verdad" de la historia, Villena utiliza la combinación prepositiva compleja a pro e acresçentamiento de para denotar el beneficio que reportaría a la población de aquel reino la comunicación de esta ciencia:

Oyendo esto Ércules, que habundava en virtudes e non fallesçié en él desseo de sçiençia nin la dispusiçión para ella, queriendo e amando que aquesta orden de sçiençias fuese comunicada segúnd nuevamente era estonçes en Libia fallado, e esto quería a pro e acresçentamiento del bien común, fue en aquellas partes, dándose al estudio e aguzándose, siquiera platicando, las intelligençia, memoria e elocuençia, que son las tres donzellas ya dichas (Cátedra 2007: 36-37).

Vinculada formal y semánticamente con la unidad descrita con anterioridad, en el marco del tercer trabajo de Hércules, relativo al episodio ya descrito de las arpías en la mesa del rey Fineo, se registra otra combinación prepositiva que resulta interesante en su contraste textual con las versiones peninsulares de materia troyana:

E dieron a la su mesa por acresçentamiento de pena la quexaçión de las arpías, que se entienden o toman por la rapaçidat o tomar avariento, faziéndolo bien paresçer tan mal fecho. E dizen que estas arpías, que son las tomas e retenimientos injustos, son aves infernales, aves porque buelan faziendo aína su obra, e infernales por la grant maliçia que en ellas ha (Cátedra 2007: 30).

Si bien el CORDE no ofrece resultados para la combinación prepositiva compleja a pro $e$ acresçentamiento de, sí que se registran desde las primeras décadas del siglo XV datos para las combinaciones prepositivas formadas de forma exclusiva con el núcleo acresçentamiento como $a$ acresçentamiento de, en acresçentamiento de y por acresçentamiento de, con variación sintácticosemántica en el uso de la preposición inicial 40 : 
Tabla 5. Representatividad de las combinaciones prepositivas con núcleo acrecentamiento

\begin{tabular}{|c|c|}
\hline Combinaciones prepositivas & Documentación en el Corpus diacrónico del español \\
\hline \multicolumn{2}{|r|}{ ACRESÇENTAMIENTO } \\
\hline a acresçentamiento de & $\begin{array}{l}\text { "a acresçentamiento de méritos" (San Vicente Ferrer, Sermones, } \\
\text { 1411-1412). }\end{array}$ \\
\hline en acresçentamiento de & $\begin{array}{l}5 \text { casos, correspondientes a los siglos XV y XVI. "en acresçentamiento } \\
\text { de honrra" (Anónimo, Privilegios de Juan II, 1411). }\end{array}$ \\
\hline por acresçentamiento de & $\begin{array}{l}2 \text { casos, ambos del siglo xV. "por acresçentamiento de virtudes" } \\
\text { (Alonso Fernández de Madrigal, Libro de las paradojas, 1437). }\end{array}$ \\
\hline \multicolumn{2}{|r|}{ ACRESCENTAMIENTO } \\
\hline a acrescentamiento de & Sin casos \\
\hline en acrescentamiento de & $\begin{array}{l}11 \text { casos, localizados los siglos XV y XVI. “en acrescentamiento de } \\
\text { méritos" (Clemente Sánchez de Vercial, Libro de los exemplos por } \\
\text { A.B.C., c. 1400-c. 1421). }\end{array}$ \\
\hline por acrescentamiento de & $\begin{array}{l}3 \text { casos, localizados a finales del siglo XV y principios del XVI. "por } \\
\text { acrescentamiento de la fee católica" (Diego de Valera, Crónica de } \\
\text { los Reyes Católicos, 1487-1488). }\end{array}$ \\
\hline \multicolumn{2}{|r|}{ ACREÇENTAMIENTO } \\
\hline a acreçentamiento de & Sin casos. \\
\hline en acreçentamiento de & $\begin{array}{l}7 \text { casos, localizados en los siglos XV y XVI, excepto el que sigue: "en } \\
\text { acreçentamiento de la sancta fe" (Don Juan Manuel, Libro de las } \\
\text { armas, posterior a 1335). }\end{array}$ \\
\hline por acreçentamiento de & $\begin{array}{l}3 \text { casos, localizados en el siglo xV, excepto el siguiente: "por } \\
\text { acreçentamiento de la sancta fe" (Anónimo, Gran Crónica de Alfonso } \\
\text { XI, c. 1348-1379). }\end{array}$ \\
\hline \multicolumn{2}{|r|}{ ACRECENTAMIENTO } \\
\hline a acrecentamiento de & $\begin{array}{l}4 \text { casos, localizados todos ellos a finales del siglo XV. "a } \\
\text { acrecentamiento de merced sobrandola" (Gonzalo García de Santa } \\
\text { María, Evangelios e epístolas con sus exposiciones en romance, ant. a } \\
\text { 1485). }\end{array}$ \\
\hline en acrecentamiento de & $\begin{array}{l}21 \text { casos, correspondientes a los siglos XV, XVI y XVII. Primer registro: } \\
\text { "en acrecentamiento de sus reinos" (Rodrigo Sánchez de Arévalo, } \\
\text { Suma de la política, 1454-1457). }\end{array}$ \\
\hline por acrecentamiento de & $\begin{array}{l}7 \text { casos, correspondientes a los siglos XV y XVI. Primer registro: "por } \\
\text { acrecentamiento de virtudes" (Gonzalo García de Santa María, } \\
\text { Evangelios e epístolas con sus exposiciones en romance, ant. a 1485). }\end{array}$ \\
\hline \multicolumn{2}{|r|}{ ACREZENTAMIENTO } \\
\hline a acrezentamiento de & Sin casos \\
\hline en acrezentamiento de & Sin casos \\
\hline por acrezentamiento de & Sin casos \\
\hline
\end{tabular}

Como puede observarse, todas las combinaciones prepositivas descritas se registran en textos de los siglos XV y XVI, y no antes ${ }^{41}$, lo que indica su representatividad y extensión en el uso en todo este tramo temporal. Como es lógico, la variante que acumula una frecuencia más alta de casos es la que coincide con el resultado gráfico del español actual. Con todo, el índice de frecuencia de uso global del conjunto de variantes reunidas no resulta significativo, si bien presenta el rasgo común de sostenerse en el tiempo. En esta descripción panorámica sobre el uso de tales combinaciones en la documentación castellana consultada, hay que destacar que, si bien se registran términos caracterizados por su condición material o física (casa, camino, etc.), la mayor parte de estas 
secuencias consideradas vehicula términos de significado abstracto como honrra, méritos, virtudes, onor, bienes, gloria, dampnaçión o afliction, entre otros.

Sin embargo, antes de la generación de estas combinaciones prepositivas en los diferentes tipos de discurso del Cuatrocientos y del Quinientos, la voz acrecentamiento, en sus múltiples formas gráficas $^{42}$, vive en la documentación castellana desde la segunda mitad del siglo XIII, según los datos ofrecidos por el CORDE43. Así, la forma <acresçentamiento> se registra por primera vez en el Libro de los estados, de don Juan Manuel, fechado entre los años 1327-1332. La forma <acrescentamiento> aparece en documentación administrativa emanada de la Corte regia de Alfonso X (1255), así como en la Estoria de España, II, fechada entre 1270-1284 según el CORDE44. Por su parte, la forma <acreçentamiento>, aparte de registrarse en documentación administrativa fechada en el primer tercio del siglo XIV, se documenta también en la Crónica de veinte reyes, fechada en la base de datos de la Real Academia Española en fecha anterior a 132545, así como en las obras de don Juan Manuel Libro de los estados (1327-1332) y Libro de las armas (posterior a 1335).

Para la forma gráfica <acrecentamiento>, codificada en el inventario léxico de la lengua española (s.v. acrecentamiento en el $\mathrm{DLE}^{23}$ ), el CORDE ofrece como primeras documentaciones el Fuero de Zorita de los Canes, fechado en torno a 1218 y 1250; la tercera parte de la General Estoria, con datación anterior a 128046, y el Libro del cavallero Zifar, fechado hacia 1300-1305, si bien conservada esta última obra en dos testimonios manuscritos del Cuatrocientos, tal como se ha descrito anteriormente. Tras estos, el siguiente dato significativo vuelve a ser el Libro de los estados de don Juan Manuel, fechado entre 1327 y 1332. Finalmente, la forma <acrezentamiento> resulta una solución gráfica marginal, pues tan solo se registra en cuatro ocasiones en textos de los siglos XVI y XVII.

Como apoyo documental a la información cronológica presentada hasta ahora, hay que destacar que los datos que nos ofrece la lexicografía histórica se orientan en la línea de lo expuesto. Así, la voz acrecentamiento se registra desde los Vocabularios generales del siglo XIV, incluidos en el Nuevo tesoro lexicográfico del español (NTLE 2007: 188. s.v. acrecentamiento), en el que se recogen asimismo las variantes gráficas accrescentamiento, acresçentamiento y cresentamiento.

De todo lo expuesto hasta ahora, podemos concluir que, si bien la voz acrecentamiento y sus correspondientes variantes gráficas parecen germinar tímidamente en la lengua castellana a partir de la segunda mitad del XIII, todo parece indicar que su uso generalizado se desarrollará durante la primera mitad del siglo XIV, y se consolidará, mediante procesos encadenados de difusión léxica a lo largo del siglo XV a través de los diferentes tipos de discurso y, en especial, a través de la tratadística de signo humanista.

La documentación textual del aragonés medieval, representada en la obra de Juan Fernández de Heredia, también ofrece testimonios variados de esta familia léxica. Así, en las Historias contra los paganos se recogen derivados romances del lat. ACCRĒSCĚRE como acrecentador, acrecentamient, acrecentar, acreciente, acrescentadas, acrescentamientos, acrescentar, entre otras formas verbales flexionadas. También en los Discursos de la guerra del Peloponeso se registran las formas acreçentat y acreçentamiento, al tiempo que en la segunda parte de la Grant Crónica de los Conquiridores se documentan las formas acrecentado, acrecentamiento, acrecentar, acrescido o acresciesse. También el Diccionario del castellano del siglo XV en la Corona de Aragón (DiCCA-XV. s.v. acrecentamiento) recoge la expresión acreçentamiento y gloria de la corona real, registrada en la Crónica de Aragón (1499). 
Finalmente, antes de abordar el análisis cronológico de la voz sinónima crecimiento y de sus variantes gráficas, apuntemos que la lengua catalana también conoció descendientes del lat. ACCRĒSCĚRE como es el caso del sustantivo acre(i)ximent, ejemplificado en estos dos casos (DCVB. s.v. acreiximent): "cell qui planta e rega vna cosa fon aquell, empero qui dona acreximent es Deus" (Traducción catalana de los Evangelios, "Còdex del Palau", [primera mitad del siglo xv]) y "en acreximent de sciencia e de virtuts" ([Documento], Archivo Municipal de Igualada, [anterior a 1484]).

En otros pasajes de Los doze trabajos de Hércules se registra lo que parece conformarse como una combinación locucional sinónima de la estudiada hasta ahora. Se trata de la unidad por cresçimiento de y de sus variantes a cresçimiento de y en cresçimiento de, representadas también en el texto que nos ocupa.

Así, en el capítulo sexto, dedicado a narrar la acción guerrera de Hércules contra Diomedes, rey de Tracia, se registra la combinación prepositiva por cresçimiento de. El sentido de esta unidad se interpreta con un contenido moral, según el cual el mercader no debe aumentar su patrimonio excesivamente, pues, si lo hace así, seguramente tendrá que cometer irregularidades en su actividad comercial, con el fin de mantener el negocio:

Este acto tan animoso e non menos virtuoso dicho fue a memoria de Ércules duradera escripto. Del qual los estados del mundo seguro e buen exemplo tomar pueden en su manera, señaladamente el estado de mercader, que non deve por cresçimiento de ganançias estender tanto su estado que después en proçeso de tiempo mantener non lo pueda sin usar de rapaçidat, engaños, usuras, megubeles e malos baratos, vendiendo falsas, encamaradas, sufisticadas e contrafechas mercadurías (Cátedra 2007: 47).

En el contexto siguiente, localizado en el trabajo séptimo, y dedicado a narrar la acción guerrera de Hércules contra la serpiente Hidra, se activa en este caso el valor semántico material al hacer referencia al sinnúmero de cabezas que la serpiente lograba germinar a medida que el héroe aqueo las cortaba:

E avía tal natura que por una cabeça de aquéllas que le fuese tajada le nasçién tres, en manera que cuanto más trabajavan en su muerte los que la querían acabar por tajamiento de aquellas cabeças, tanto más ella por su natura multiplicava en su vida por cresçimiento de cabeças. E por cada cabeça que le cresçía ella usava de nuevas fuerças e más dañosos empesçimientos, en tanto que los habitantes de aquella región non podién sobrelevar tanto embargo nin temprar tan poderoso mal (Cátedra 2007: 49).

Un tercer dato contextual en el que se registra la combinación locucional por cresçimiento de se localiza en el octavo trabajo, en el que Hércules vence al gigante Atheleo en respuesta al rapto de Daimira por parte de este último. En el desarrollo alegórico de esta historia, Hércules representa el buen propósito del hombre armado con las cualidades de la virtud y de la fortaleza moral, mientras que Daimira representa la vida virtuosa, que cuesta trabajo encontrar y mantener. Atheleo representa al mundo que, bajo diferentes apariencias, intenta alejar de esa buena vida al virtuoso. A diferencia de los pasajes anteriores, el sentido de la combinación considerada resulta abstracto:

Estonçes fará matrimonio con la buena vida legítimo e bueno, la cual, pues que la avrá juntado consigo, non la deve dexar sinon por cresçimiento de mayor virtud; ca estonçes, pues contiene buena vida, non se disuelve el matrimonio con el virtuoso bevir, ca ésta es muger real, mostrando que por virtud los reyes son dignos del mayor grado entre los omnes (Cátedra 2007: 56). 
De forma complementaria a los datos contextuales descritos hasta ahora, en otros pasajes también se registran las variantes locucionales a cresçimiento de y en creçimiento de, en las que persiste ese sentido abstracto:

[...] non aviendo respecto a la rudidat de la ordinaçión e escuridat de sentençias, e la comuniquedes en lugar que faga fructo e de que tomen enxemplo, a cresçimiento de virtudes e purgamiento de viçios. Así será espejo actual a los gloriosos cavalleros en armada cavallería, moviendo el coraçón de aquéllos en non dubdar los ásperos fechos de las armas e emprender grandes e honrados partidos, enderesçándose a sostener el bien común, por cuya razón cavallería fue fallada (Cátedra 2007: 16).

Considere el cavallero que, pues los mayores de sí deve reprehender de viçios, él deve seer del todo apartado de aquéllos. E si a los enemigos vesibles ha de contradezir, non le conviene a los invisibles subjudgarse. E pues quiere gozar de la honra e previlegio de cavallero, sepa levar las cargas a que es obligado; sea exemplo, así como Hércules, en su estado e persevere en creçimiento de bien en mejor, segúnd se requiere a la virtuosa e cavalleril vida. E así faziendo, los subçesores avrán d'esto fazaña e serán movidos a loar e seguirles, sabiendo de sus victorias (Cátedra 2007: 33).

La primera documentación que ofrece el CORDE para la voz crecimiento bajo la forma gráfica <cresçimiento> es en torno a 1277, en la obra del rabí Zag Libros del astrolabio llano47. Resulta cuando menos curioso el salto temporal entre esta primera mención y la siguiente, correspondiente a documentación privada (1348). Tras estos dos casos, la voz se registrará en la primera partida de la Grant Crónica de Espanya (1385) y en las obras de Villena Exposición del salmo "Quoniam videbo" y la Traducción y glosas de la Eneida. Para la forma <crescimiento> el coRDE ofrece como primera documentación Bocados de oro (c. 1250), si bien hay que tener presente que la edición utilizada en esta base de datos toma como texto base el manuscrito $m$, datado en el siglo XV (Haro Cortés 2002: 226) ${ }^{48}$, si bien "mejorándolo con $o, n, q$ y con $e$, $s$ " (Haro Cortés 1996: 13). El dato siguiente corresponde al Lapidario, de Alfonso X (c. 1250). La forma gráfica <creçimiento> se registra también desde la segunda mitad del siglo XIII; concretamente, en el Setenario (c. 12521270) de Alfonso X. Para la forma <crecimiento>, el condE la registra en el Libro conplido en los judizios de las estrellas, fechado en torno a 1254-1260. Finalmente, la forma <crezimiento $>$, con un carácter marginal con respecto al resto de variantes gráficas, se registra tan solo en once ocasiones con un primer registro en la obra poética de Suero de Ribera (anterior a 1400 - anterior a 1440).

Si bien la voz crecimiento, con sus correspondientes formas gráficas, se registra desde los primeros textos literarios en lengua castellana y, en especial, en la prosa de Alfonso X, el registro de las secuencias prepositivas a crecimiento de, en crecimiento de y por crecimiento de, con sus correspondientes variantes gráficas, si bien aparecen de forma testimonial con un solo caso desde los primeros años del siglo XIV, no se generalizarán hasta bien entrado el siglo XV, tal como podemos comprobar en esta tabla adjunta: 
Tabla 6. Representatividad de las combinaciones prepositivas con núcleo crecimiento

\begin{tabular}{|c|c|}
\hline Combinaciones prepositivas & Documentación en el Corpus diacrónico del español \\
\hline \multicolumn{2}{|r|}{ CRESÇIMIENTO } \\
\hline a cresçimiento de & Sin casos \\
\hline en cresçimiento de & $\begin{array}{l}\text { "en cresçimiento de mayores bienes" (A. de Villalpando, } \\
\text { Razonamiento de las Reales Armas de los Católicos Reyes, c. 1474- } \\
\text { 1500). }\end{array}$ \\
\hline por cresçimiento de & Sin casos \\
\hline \multicolumn{2}{|r|}{ CRESCIMIENTO } \\
\hline a crescimiento de & Sin casos \\
\hline en crescimiento de & $\begin{array}{l}\text { "en crescimiento de muchos más reinos" (G. Fernández de Oviedo, } \\
\text { Historia general y natural de las Indias, 1535-1557). }\end{array}$ \\
\hline por crescimiento de & “por crescimiento de las usuras” (Anónimo, Vidal Mayor, c. 1250). \\
\hline \multicolumn{2}{|r|}{ CREÇIMIENTO } \\
\hline a creçimiento de & $\begin{array}{l}\text { "[a ondra e] a creçimiento de la çipdat" (Anónimo, Fuero de Alarcón, } \\
\text { 1300). }\end{array}$ \\
\hline en creçimiento de & $\begin{array}{l}\text { "en creçimiento de gente de armas" (Anónimo, Crónica incompleta } \\
\text { de los Reyes Católicos, 1469-1476). }\end{array}$ \\
\hline por creçimiento de & Sin casos \\
\hline \multicolumn{2}{|r|}{ CRECIMIENTO } \\
\hline a crecimiento de & $\begin{array}{l}\text { "a crecimiento de la cibdat" (Anónimo, Fuero de Alcaraz, ant. a } \\
\text { 1296) }\end{array}$ \\
\hline en crecimiento de & $\begin{array}{l}3 \text { casos, correspondientes a los siglos XVI y XVII. Primer registro: “en } \\
\text { crecimiento de ciento y cincuenta” (Anónimo, Relaciones histórico- } \\
\text { geográficas-estadísticas de los pueblos, 1575-1580). }\end{array}$ \\
\hline por crecimiento de & $\begin{array}{l}\text { "por crecimiento de los básidos" (Casildo Ascárate y Fernández, } \\
\text { Insectos y criptógamas que invaden los cultivos en España, 1893). }\end{array}$ \\
\hline \multicolumn{2}{|r|}{ CREZIMIENTO } \\
\hline a crezimiento de & Sin casos \\
\hline en crezimiento de & Sin casos \\
\hline por crezimiento de & Sin casos \\
\hline
\end{tabular}

En una línea similar de discusión filológica, es curioso observar que, en el caso de la voz crecimiento, pese a su documentación temprana en los textos, su inserción en la tradición lexicográfica no se da hasta bien entrado el siglo xv, con el glosario de la Biblia de Arragel, que supone su primera mención. Tras esta, se codificará de forma ininterrumpida en las sucesivas obras lexicográficas. En ellas se registrarán variantes gráficas como creçimiento, crescimiento, cresçimjento y criescimiento (NTLE 2007: 3051. s.v. crecimiento).

Con respecto a la voz catalana creixement, el cICA registra la variante gráfica <creximent $>$ desde la segunda mitad del siglo XIII en textos como la Crònica de Bernat Desclot ("Com nós, pare sant, siam passats en la terra de Barberia e ajam presa aquí terra a honor de Déu e a creximent de tota crestiantat"), la obra Costums de Tortosa o començaments de medicina, donde se registra por primera vez la secuencia locucional per creximent de, si bien todavía sin haber completado su 
proceso histórico de desemantización: "et la qual no·s consuma per aminvament de grosea, ni per creximent de gruxa no muntiplica”. En cualquier caso, esta variante locucional presentará un desarrollo ininterrumpido a lo largo de los siglos XIV y XV, visible en textos como Furs de València, el Llibre de meravelles, la Crònica de Ramon Muntaner, la Doctrina pueril luliana, el Regiment de preservació de la pestilència o el Epistolari de Ferran I d'Antequera. Tal como se ha descrito anteriormente para la lengua castellana, también la documentación catalana nos muestra que a partir del siglo XV se produce un incremento en el uso de las combinaciones prepositivas como $a$ creximent de, ab creximent de, en creximent de o per creximent de, amén de otras secuencias complejas como en creximent e perseverança de virtuts, representada en el Epistolari de la València medieval.

Por su parte, la forma gráfica <crexement> se registra en doce ocasiones desde la segunda mitad del siglo XIV, según los datos aportados por el CICA. Al igual que en el caso de la forma <creximent>, también en este caso hay que esperar al Cuatrocientos para registrar secuencias locucionales del tipo ab crexement de, documentadas en el Epistolari de Ferran d'Antequera: "Lo Creador de totes coses, senyor molt alt, faça viure e regnar longament vostra alta senyoria $a b$ crexement de sa reyal corona".

También en este caso los datos de la lexicográfica histórica catalana corroboran la información cronológica esbozada. Así, tanto el Diccionari català-valencià-balear como el Diccionari etimològic i complementari de la llengua catalana (1980-2001: II, 1037) atestiguan su presencia ininterrumpida desde el último cuarto del siglo XIII en la obra de Ramon Llull ${ }^{49}$. Esta última obra lexicográfica incluye, a su vez, las variantes antiguas creiximent y acreiximent, atestiguadas en documentos del siglo XIV.

En los textos heredianos se registra la forma crecimiento en la primera partida de la Grant Crónica de los Conquiridores y en la tercera partida de la Grant Crónica de Espanya. En la primera compilación mencionada, junto a la forma crecimiento, se registran también crescimiento y creximiento, además del participio de presente crescient. Resulta sobre todo muy significativa la variante gráfica creximiento por su vinculación al catalán en razón de un idéntico resultado fónico [ ] ]derivado de la evolución del grupo consonántico -SK-, y representado gráficamente en $<\mathrm{X}>$. Esta forma aparece registrada en la Grant Crónica de los Conquiridores, flexionada en formas verbales como crexer, crexeran, crexia, crexida, crexido, crexient o crexiessen. También en la tercera partida de la Grant Crónica de Espanya, junto a la forma crecimiento, se registran formas vinculadas al catalán como crexer, crexida, crexient o crexio.

De igual modo, en la traducción aragonesa de las Historiae adversus paganos de Paulo Orosio se registran los dos haces de reflejos romances descritos hasta ahora, con resultados fónico-gráficos complementarios: de un lado, las formas vinculadas a la lengua castellana crescer, crescido, crescientes, crescieron o cresciesse y, de otro, las formas paralelas a los resultados a que llegó el catalán en crexe, crexent, crexia, crexida, crexieron, creximiento o crexio. También en el Eutropio, texto calificado por Geijerstam (1989: 509) como el más catalanizado y, al mismo tiempo, el más corrupto de todas las obras que conforman el corpus herediano, se registran los dos haces de formas paralelas: junto a crecio, crecia, crecer, crescida o crescio se documentan crexe, crexer y creximiento.

Pues bien, en la Historia destructionis Troiae, en el pasaje referido a la invitación que el rey Peleo dirige a su sobrino Jasón para que intente conquistar el vellocino de oro, el narrador avanza que 
las intenciones del tío no se corresponden con lo que espera su sobrino, pues ese ofrecimiento no se orienta a incrementar su honor, sino justamente a dañar a su persona:

Intellectis igitur a Iasone singulis que in tantorum presencia circumstantium rex Pelleus protulit, gaudio exillaratus est multo, non attendens insidiosas regis austutias et eius dolositatis latebras non aduertens, ratus que dixerat de pure regis consciencie cellulla processisse potius in sui honoris incrementa sublimia quam in sue detrimenta persone (Historia destructionis Troiae [c. 1287]. Griffin 1936: 8).

Tabla 7. Resultados de vulgarización del texto latino in sui honoris incrementa

\begin{tabular}{|l|l|}
\hline \multicolumn{1}{|c|}{$\begin{array}{c}\text { Històries troianes (1367-1374) } \\
\text { (Perujo Melgar 2015: 25) }\end{array}$} & \multicolumn{1}{c|}{$\begin{array}{c}\text { Libro de la historia troyana (1443) } \\
\text { (Peláez Benítez 1999: 122) }\end{array}$} \\
\hline $\begin{array}{l}\text { Enteses, adonchs, per Jàson totes aquellas } \\
\text { coses les quals lo rey Peleu hac dites en } \\
\text { presència de la dita cort e de tants nobles, } \\
\text { alegrà's en son coratge de gran goig, no } \\
\text { penssant les estúcies anganoses del dit rei, ne } \\
\text { avertint a la intenció malvada per la qual ell li ho } \\
\text { deya, penssant que allò li digués e procehís de la la } \\
\text { sua pura consciència per creximent de sa honor } \\
\text { més que per dempnatge de la sua persona. }\end{array}$ & $\begin{array}{l}\text { Entendido por Jasón todo lo por el rey, su tío } \\
\text { dicho en presencia de tantos nobles presentes, } \\
\text { fue muy gozoso, non advirtiendo a las } \\
\text { astuciosas asechanças e encubiertos engaños } \\
\text { del rey, creyendo con firmeza que las cosas por } \\
\text { inticos de su concencia, en }\end{array}$ \\
\hline
\end{tabular}

Al igual que en los pasajes descritos de Los doze trabajos de Hércules, también en estos fragmentos correspondientes a las versiones peninsulares de materia troyana las secuencias prepositivas per creximent de y en acrescentamiento de vehiculan un contenido abstracto, representado en este caso por el SN sa honor / su honor.

Sin embargo, tal como puede apreciarse en los resultados de vulgarización de las traducciones al catalán y al castellano de la obra historiográfica de Guido delle Colonne ${ }^{50}$, se da una divergencia formal clara entre ambas versiones. El texto catalán opta por utilizar la unidad léxica creximent, voz genuina y con una tradición literaria consolidada desde la segunda mitad del siglo XIII. Por su parte, la versión castellana de 1443, en concordancia con los datos de frecuencia en el uso de la combinación prepositiva por acresçentamiento de y sus respectivas variantes fraseológicas, expresa tal contenido mediante la voz acrescentamiento.

En este sentido, hay que recordar que el texto de Villena recurre de forma mayoritaria a la voz cresçimiento para expresar el valor nocional de 'incremento' referido al honor mediante la combinación de tipo prepositivo por cresçimiento de y sus respectivas variantes fraseológicas. Recordemos también que, si bien en la documentación procedente del corpus literario de Juan Fernández de Heredia se registran tanto las formas próximas a la lengua castellana (cresçer, cresçiente, cresçimiento, etc.) como las formas vinculadas a la lengua catalana (crexer, crexient, creximiento, etc.), la similitud formal de estas últimas con relación al resultado fraseológico del texto de Villena por cre(s)çimiento de nos permite trazar una vía de comunicación cultural entre el ámbito específico de la obra herediana, el universo cultural de la Corona de Aragón y el quehacer literario de Enrique de Villena51. 
De forma análoga, y en calidad de refuerzo explicativo de cuanto se acaba de afirmar, hay que señalar dos datos complementarios sobre la datación y vitalidad de las combinaciones prepositivas sinónimas en acresçentamiento de y en cresçimiento de, con sus respectivas variantes. Si nos basamos en los datos acopiados en la tabla 5 sobre la línea cronológica de las secuencias conformadas con la voz nuclear acresçentamiento, habría resultado esperable que Villena hubiese empleado esta unidad de forma sistemática, puesto que se trata de la opción de uso generalizada en la lengua castellana a partir del siglo XV, en detriminiento seguramente de la combinación sinónima en cresçimiento de que, a la débil presencia en los textos, hay que sumar su falta de documentación en el tramo temporal estudiado. Por otra parte, hay que recordar que las variantes con preposición inicial por (por cresçimiento de, por crescimiento de, por creçimiento de y por crecimiento de) no presentan registros en la documentación aducida, a excepción del caso aislado del testimonio del Vidal Mayor (c. 1250), texto vinculado al romance navarro (González Ollé 2004) y, por tanto, al área lingüística del Oriente peninsular.

Más difícil resulta demostrar la filiación textual con la versión catalana de la Historia destructionis Troiae, a pesar de su coincidencia formal. Si bien la combinación prepositiva per creximent de no se registra con una frecuencia alta en los textos medievales catalanes y, en cambio, sí que aparece representada en esta traducción catalana de la Historia trojana (c. 1287) de Guido delle Colonne, a la falta de noticias detalladas sobre si Enrique de Villena tuvo acceso a esa versión, se suma a ello la idea nebulosa de hasta qué punto se puede adscribir esa elección estilística al recuerdo de una lectura particular.

\section{RESULTADOS Y CONCLUSIONES GENERALES}

El estudio histórico de la fraseología delineado en estas páginas ha pretendido conocer de manera profunda y lo más exacta posible los modelos prosísticos en que se asientan algunas de las elecciones estilísticas que Enrique de Villena llevó a cabo en Los doze trabajos de Hércules. En el análisis trazado, articulado en torno a la descripción detallada de la trayectoria histórica de cuatro combinaciones fraseológicas, se ha creído advertir continuidades de estilo que pasamos a resumir y valorar con la atención individuada a cada secuencia locucional.

En el caso de la unidad en una compañía e de un coraçón, se ha podido constatar en primer lugar que su estructura gramatical compleja no es exclusiva de nuestro texto, pues se registra tanto en la documentación castellana (en una voluntad e querer) como en la catalana (d'un cor e d'una voluntad o de un cor e de un voler), de modo que, si bien la secuencia en una compañía e de un coraçón se registra de forma exclusiva y única en Los doze trabajos de Hércules según el CORDE, no podemos considerar que se trate de una innovación estilística de Villena, sino que su uso tanto en la autotraducción castellana como, probablemente, en su versión original catalana responde a técnicas retóricas heredadas.

Con relación a la historicidad de estas dos secuencias locucionales amalgamadas, se ha podido constatar que la unidad de un coraçón se encuentra ampliamente documentada en castellano desde la segunda mitad del siglo XIII, así como en catalán en los principales textos cronísticos, por lo que hay que pensar que esta unidad se encontraba plenamente consolidada en el momento en que Villena escribe su obra. Otro tanto cabe afirmar de la secuencia en una compañía, registrada desde los primeros tramos temporales en el desarrollo literario de ambas lenguas. Con todo, a pesar de que se constata esta profundidad histórica en el empleo literario de tales combinaciones, es 
importante no perder de vista las unidades ab gran companya e ab gran poder y de un cor e de un voler, próximas a la secuencia en una compañía e de un coraçón, y registradas en Lo crestià (c. 13791382) de Francesc Eiximenis, con quien nuestro autor tuvo un contacto directo en la corte ducal de Gandía.

El caso de la secuencia lexicalizada con mano fuerte resulta distinto, pues, como se ha tenido ocasión de comprobar, su presencia en la documentación castellana resulta testimonial hasta bien entrado el siglo $\mathrm{XV}^{52}$, y posterior, en todo caso, a su registro profuso en los textos catalanes $\mathrm{y}$ aragoneses con las combinaciones ab mà fort y en mano fuert. Igual trazo diacrónico ofrece el seguimiento de la locución con mano poderosa, con primeras menciones en la obra de Juan Fernández de Heredia, y registrada en la documentación catalana en su forma ab mà poderosa desde la segunda mitad del siglo XIV, frente a su frecuencia escasa en textos castellanos.

Todo ello parece sugerir que Villena pudo asimilar estos módulos expresivos en términos de continuidad estilística, por lo que podrían catalogarse como posibles casos de transferencia fraseológica, teniendo en cuenta el contexto cultural en que se formó nuestro autor tanto en la corte ducal de Gandía como en la corte barcelonesa. Si a ello sumamos el testimonio aducido de sor Isabel de Villena en su Vita Christi, parece evidente que el uso de la secuencia locucional con mano fuerte en Los doze trabajos de Hércules ha de relacionarse forzosamente con el espacio cultural de la Corona de Aragón. No así en el caso de la secuencia locucional con mano de fortaleza, registrada de forma exclusiva en el texto que nos ocupa y sin trazas de uso en la documentación aragonesa y catalana, lo que nos lleva a plantear la posibilidad de que sea el resultado de una variatio estilística en el texto de Villena.

El análisis diacrónico de la secuencia locucional prepositiva a consejo e induzimiento de refleja una línea cronológica y geolectal muy similar a la planteada anteriormente para las unidades fraseológicas con mano fuerte y con mano poderosa. Como se ha constatado, la secuencia a consejo e induzimiento de no se registra en CORDE, y las secuencias emparentadas a induzimiento de o por induçimiento de se presumen posteriores en el tiempo o, al menos, contemporáneas al uso estilístico en el texto de Villena. Por el contrario, tanto la profundidad histórica de la voz induïment en catalán, registrada en las Vides de sants rossellonesos (c. 1260), como el registro en aragonés cancilleresco de la voz induzimiento (cfr. Carta del rey Jaime II a doña María de Molina, de 1319), nos ofrecen un mapa de difusión léxica cuyo centro de irradiación parece situarse en el Oriente peninsular, constatable en sintagmas prepositivos en vías de lexicalización como induzimiento et consello o sense induïment ne consell, en los que se aprecia la coaparición continuada de tales voces, y en las que se podría conjeturar una probable marcación diatécnica de ámbito jurídico, enmarcada en la prosa de la Cancillería aragonesa. A este respecto, merece la pena destacar las palabras siguientes de Cátedra (1988: 139), tan llenas de sentido en relación con la interpretación esbozada:

Y es que cuando don Enrique utiliza giros como «cosa pública» (que M. Morreale califica con razón como «hermoso latinismo») u otros no se enganchaba al tren del civilismo humanista, sino que reproducía formas estilísticas que se hallan en los cancilleres aragoneses, y hasta en Eiximenis.

En calidad de unidad sinónima, la secuencia a inducción de ofrece resultados idénticos, pues en la documentación castellana catalogada en CORDE los primeros registros se corresponden con la obra literaria de Enrique de Villena, así como con el Libro de las donas (anterior a 1448) de Francesc Eiximenis. La documentación catalana ofrece también menciones de esta voz desde la primera mitad del siglo XIV, y lo que es más importante, la mayor parte de esos datos se 
corresponde con la secuencia prepositiva a inducció de, lo que manifiesta su grado progresivo de consolidación y la posibilidad de que pueda ser transferida a otros entornos textuales. También en la prosa de la Grant Crónica de Espanya se registra una primera mención de la variante a induçion $d e$, así como en otras creaciones heredianas se documentan combinaciones como a inducción e amonestación de o a induction e solicitut de, lo que nos lleva a afirmar que esta voz también presentaba un grado avanzado de aclimatación en el desarrollo de la prosa medieval aragonesa. Parece evidente, pues, que el centro de irradiación de esta secuencia locucional registrada en la obra de Villena se localiza de nuevo en la prosa cancilleresca, así como en los modelos prosísticos de signo historiográfico emanados de la Corona de Aragón:

Ello es que en los tiempos en que don Enrique está mamando la «leche retorical», que dirá luego con todos los resabios pedagógicos del mundo, se está fraguando un estilo cancilleresco, básico para saber de la prosa romance del siglo XV en el reino de Aragón, de la que algunos han datado su venida a esta mundo de la mano partera de Antoni Canals, el servidor que mencionábamos del abuelo don Alfonso, al que dedicó su Scipió e Aníbal, obra redactada ya en esa florida valenciana prosa, allá por los años en que despertaba o maduraba intelectualmente el nieto don Enrique (Cátedra 1988: 128).

En este entramado de vías multidireccionales de comunicación cultural, la traducción a la lengua castellana de la Divina Comedia que Villena realiza entre los años de 1427 y 1428 por encargo de D. Íñigo López de Mendoza resulta también un claro exponente de aculturación léxica (Pascual 1974) y fraseológica (Vicente Llavata en prensa a) entre los dominios geográficos del Oriente peninsular. Si bien Villena intenta recurrir siempre a una solución léxica de base castellana antes de optar precipitadamente por un préstamo, lo cierto es que la influencia cultural y lingüística del oriente peninsular en la Castilla del siglo XV tiene en este ejercicio extremado de traducción una muestra sobresaliente:

Lo paradójico de nuestra traducción es que, siéndolo de una obra italiana en una prueba de que el traductor sabía catalán; pero éste es un hecho biográfico sin apenas trascendencia, lo importante es su valor de síntoma, en cuanto marca una dirección cultural catalanista en el siglo XV (que normalmente se tiene menos en cuenta que la italiana, máxime cuando muchos de aquellos escritores dan pruebas explícitas, biográficas y literarias de su orientalismo). El que el lenguaje de los catalanes resulte más fácil de entender y más familiar que el de los italianos, el que los catalanes viajaran por Italia mucho más que los castellanos, junto al alto nivel de la cultura catalana, eran hechos que iban a influir en que en muchas ocasiones las novedades de Italia se divulgaran a Castilla desde Cataluña (Pascual 1974: 206).

Y todo ello tendrá su continuidad en la obra literaria de Íñigo López de Mendoza, quien, siguiendo las enseñanzas literarias de su mentor Enrique de Villena en el período de su estancia formativa en la corte real de Alfonso V de Aragón, abrazará los códigos culturales en boga en un espacio geográfico de verdadera efervescencia artística e intelectual como lo fue la Corona de Aragón desde finales del siglo XIV, lo que se manifestará igualmente en la transferencia de voces y unidades fraseológicas en forma de préstamos ${ }^{53}$ :

La estancia de Íñigo López en la corte de Alfonso V le dio ocasión para conocer horizontes literarios no atalayados desde Castilla. Extraño para un castellano hubo de ser el sentimiento de viva y directa continuidad que los poetas catalanes mantenían con los antiguos trovadores occitánicos (Lapesa 1957: 38-39). [...] Hay en el léxico del Marqués, como en toda la literatura castellana de su tiempo, un estrato ya viejo de procedencia francesa o provenzal, al que la vida de corte había añadido préstamos recientes (cota, coser, page, galante, balada, rondeles, etc.) [...] Es probable que en algún caso no se trate de influjo francés, sino catalán; catalanismos parecen brugido 'ruido', todas horas 'siempre' o todo solo 'solo' (Lapesa 1957: 167-168). 
Frente a la coincidencia en el trazado de líneas cronológicas y geolectales entre las unidades $a$ induzimiento de y a inducción de, que llegan a converger en la obra de Villena desde los modelos prosísticos forjados en los dominios del Este peninsular, el caso de las combinaciones sinónimas $a$ pro e acresçentamiento de, por acresçentamiento de y por cresçimiento de, con sus respectivas variantes, resulta claramente distinto en su germinación y desarollo. Para empezar, la voz acresçentamiento presenta una profundidad histórica en la lengua castellana desde la segunda mitad del siglo XIII, lo cual se refleja en su temprana precodificación en los Vocabularios generales del siglo XIV. Con todo, hay que apuntar que la aclimatación de secuencias prepositivas como las registradas en la obra de Villena no llega a generalizarse antes de la primera mitad del siglo XV, si bien es evidente que se trata de un proceso de codificación fraseológica autóctono, paralelo al desarrollo de la prosa castellana cuatrocentista. En cualquier caso, es importante destacar que la secuencia prepositiva a pro e acresçentamiento de se registra como testimonio único en Los doze trabajos de Hércules.

Con respecto a la combinación sinónima, por creçimiento de y sus variantes a cresçimiento de y en creçimiento de, se reproducen, en buena medida, las líneas cronológicas resumidas en la síntesis anterior. Así, en su condición de reflejos del lat. CRESCĒRE, tanto la lengua castellana como el resto de romances hispánicos desarrollaron las secuencias prepositivas analizadas, si bien no se generalizaron hasta mediados del siglo XV. Con todo, sorprende el uso recurrente en Villena de las secuencias prepositivas con núcleo cresçimiento y con preposición inicial por, esquema gramatical que comparte tanto con el dato del Vidal Mayor como con el ejemplo de la versión catalana de la Historia destructionis Troiae, frente al registro predominante de variantes locucionales con preposición inicial a y en en la documentación castellana examinada. Tampoco debería dejarse de lado el registro de la forma aragonesa creximiento, que podría conformarse como una suerte de estación de enlace entre ambos dominio lingüísticos.

Respecto de la hipótesis de trabajo con la que se ha operado en este artículo, esto es, si la tradición narrativa de materia troyana puede considerarse una fuente indirecta en el estado de redacción de Los doze trabajo de Hércules, lo cierto es que, partiendo del aserto de Morreale (1958), Villena estaba familiarizado con la Historia destructionis Troiae, aunque desconocemos si tuvo acceso a las versiones peninsulares derivadas del texto latino o si, tan solo, conocía el texto latino. En el análisis fraseológico y contrastivo presentado, el texto de Villena coincide mayoritariamente con los resultados de vulgarización de la versión catalana - ab mà poderosa / con mano poderosa, per creximent de / por cresçimiento de y a inducció/induïment de / a consejo e induzimiento de- y, en menor medida, con los resultados de la aragonesa -todos de un coraçón / de un coraçón y a consejo e induzimiento de- y con los de la castellana - en acresçentamiento de / a pro $e$ acresçentamiento de y por acresçentamiento de-, lo que podría abrir una discusión en torno a si tales coincidencias en el empleo de unas mismas unidades cabría entenderlas como continuidades estilísticas, con su consiguiente contribución a su grado progresivo de codificación fraseológica.

Resulta evidente que el mayor escollo en esta discusión reside en el hecho de que la mayor parte de las combinaciones fraseológicas en las que se ha advertido esa continuidad estilística vive en la documentación catalana y aragonesa desde la segunda mitad del siglo XIII, en el marco amplio del desarrollo del discurso prosístico en los diferentes espacios peninsulares, con lo que las posibilidades de que Villena haya podido inspirarse en otras lecturas se multiplican.

Sin embargo, independientemente de este dato indiscutible de historicidad, lo que habría que dilucidar aquí es si Villena, valiéndose del valor ejemplarizante común que comparten tanto el 
texto villenesco como la tradición narrativa de materia troyana ${ }^{54}$, así como de una concepción afín en el modo de recrear los hechos pasados bajo la etiqueta de la "narración fabulosa" de Macrobio, podría haber utilizado esas combinaciones fraseológicas con una finalidad textual delimitada: conformarse como anclajes estilísticos a la hora de subrayar y reforzar esa "verdad histórica", presente en la tradición narrativa de materia troyana, y que Villena se hubiera planteado aplicar también a los hechos gloriosos de Hércules. Parece, pues, que solo desde el potencial estilístico que estas unidades irradian en el marco de una concepción acotada de la comunicación literaria podría llegar a defenderse un uso deliberado de tales módulos expresivos en Los doze trabajos de Hércules de Enrique de Villena.

En cualquier caso, de acuerdo con los datos presentados, y considerando que todo estudio adolece de sus propias limitaciones interpretativas, resulta una evidencia que Enrique de Villena tiene muy presentes los artificios retóricos provenientes tanto de la prosa cancilleresca escrita en catalán y en aragonés como de los modelos prosísticos de signo historiográfico desarrollados en el ámbito cultural de la Corona de Aragón. Si todo ello se contextualiza en un procedimiento traductológico basado en un cierto automatismo en la búsqueda afanosa de correspondencias léxicas y fraseológicas entre dos sistemas lingüísticos estrechamente emparentados, se explica que Enrique de Villena se oriente en su ejercicio audaz de autotraducción hacia soluciones vinculadas a las modalidades lingüisticas del Este peninsular, en una espiral inagotable de plena efervescencia creativa.

\section{Corpus}

Álvarez Rodríguez, A. (ed.) (2009 [1983]): Vidas semblantes. Versión aragonesa de las Vidas paralelas patrocinada por Juan Fernández de Heredia. Zaragoza: Prensas de la Universidad de Zaragoza.

ARBESÚ, D. (ed.) (2011): Textos y concordancias de la Fazienda de Ultramar. Hispanic Seminary of Medieval Studies: http://www.hispanicseminary/t\&c/ac/index.htm [27/03/2020].

CÁtEDRA, P. M. (ed.) (1994): Obras completas de Enrique de Villena. Madrid: Turner.

CÁTEDRA, P. M.; CHERCHI, P. (2007): Los doce trabajos de Hércules (Zamora, Antón de Centenera, 1483) [Ed. de Pedro. M. Cátedra]. Santander: Universidad de Cantabria, 2 vols.

CICA = Corpus Informatitzat del Català Antic (2008): J. Torruella (dir.), junto con M. Pérez Saldanya y J. Martines. http://seneca.uab.es/sfi/cica [10/03/2019].

CORDE = Real Academia Española: Banco de datos (CORDE) [en línea]. Corpus diacrónico del español. http://www.rae.es [15/03/2020].

$D A=$ Real Academia Española: Diccionario de autoridades [en línea]. https://webfrl.rae.es/DA.html [15/03/2020].

DCECH = Corominas, J.; Pascual, J. A. (1980-1991): Diccionario crítico etimológico castellano e hispánico. Madrid: Gredos, 6 vols.

DCVB = Alcover, A. M.ä; de Borja Moll, F.; Moll, A.; Sanchis Guarner, M. (1993 [1964-1969]): Diccionari catalàvalencià-balear. Palma: Editorial Moll.

DECat = Coromines, J.; Gulsoy, J.; Cahner, M. (1980-2001): Diccionari etimològic i complementari de la llengua catalana. Barcelona: Edicions catalanes Curial, 10 vols. 
DiCCA-XV = Lleal Galceran, C. (dir.): Diccionario del castellano del siglo XV en la Corona de Aragón, Grup d'Història i Contacte de Llengües (GHCL) [en línea]: <http://stel.ub.edu/diccaxv/home/index/myLanguage:es>. Barcelona: Universidad de Barcelona [30/11/2019].

DLE = Real Academia Española (2014): Diccionario de la lengua española. Madrid: Espasa.

GAGO Jover, F. J. (2011-.): Textos navarro-aragoneses. Digital Library of Old Spanish Texts. Hispanic Seminary of Medieval Studies: http://www.hispanicseminary/t\&c/ac/index.htm. [27/03/2020].

GEIJERSTAM, R. af (ed.) (1964): La Grant Crónica de Espanya, libros I-II: edición según el ms. 10133 de la Biblioteca Nacional de Madrid. Uppsala: Uppsala University.

GRIFFIN, N. E. (ed.) (1936): Historia destructionis Troiae. Massachusetts: The Mediaeval Academy of America.

LAZAR, M. (ed.) (1965): La Fazienda de Ultra Mar, Biblia Romanceada et Itinéraire Biblique en prose castillane du XIIe siècle. Salamanca: Acta Salmanticensia.

Morreale, M. (ed.) (1958): Los doze trabajos de Hércules. Madrid: Real Academia Española.

NTLE = Alvar Ezquerra, M.; Nieto Jiménez, L. (2007): Nuevo tesoro lexicográfico del español (s. XIV-1726). Madrid: Arco/Libros.

NTLLE = Real Academia Española: Banco de datos (NTLLE) [en línea]. Nuevo tesoro lexicográfico de la lengua española. http://www.rae.es [23/03/2020].

Peláez BeníTEZ, M. a D. (ed.) (1999): Libro de la historia troyana. Madrid: Editorial Complutense.

Pelletier Norris, F. (ed.) (1970): La coronica troyana: a medieval Spanish translation of Guido de Colonna's Historia Destructionis Troiae. Chapell Hill: The University of North Carolina Press.

Perujo Melgar, J. M. (2015): Les Històries troianes: estudi i edició, tesis doctoral dirigida por R. Alemany Ferrer. Alicante: Universidad de Alicante.

Romero CAmbrón, Á.; García Pinilla, I. J. (eds.) (2008): Historias contra los paganos. Zaragoza: Prensas de la Universidad de Zaragoza.

SANZ Julián, M. (ed.) (2012): Crónica troyana. Zaragoza: Prensas de la Universidad de Zaragoza.

\section{Bibliografía}

Cacho Blecua, J. M. (1997): El Gran Maestre Juan Fernández de Heredia. Zaragoza: Caja de Ahorros de la Inmaculada.

CAMPa GutiÉRREZ, M. DE LA (2003): “Crónica de veinte reyes”, Revista de Literatura Medieval 15/1, pp. 141156.

CAnTAVElla, R. (2015): "Isabel de Villena i família: una reconsideració biogràfica”, Anuario de Estudios Medievales 45/2, pp. 715-732. https://doi.org/10.3989/aem.2015.45.2.03

CASAS Rigall, J. (1999): La materia de Troya en las letras romances del siglo XIII hispano. Santiago de Compostela: Universidade de Santiago de Compostela.

EBEREnZ, R. (1995): "La catalanitat “subjacent" de l"Arte Cisoria' d'Enric de Villena", in J. Massot i Muntaner (ed.): Miscel·lània Germà Colón, 4. Barcelona: Abadia de Montserrat, pp. 95-106.

CATEDRA, P. M. (1981): Para el estudio de la biografía y la obra de Enrique de Villena, tesis doctoral inédita. Bellaterra (Barcelona): Universitat Autònoma de Barcelona, 9 vols. 
CÁtedRA, P. M. (1988): “Sobre la obra catalana de Enrique de Villena”, in L. López Grijera y A. Redondo (eds.): Homenaje a Eugenio Asensio. Madrid: Gredos, pp. 127-140.

CÁtedra, P. M. (2002): “Enrique de Villena”, in C. Alvar y J. M. Lucía Megías (dirs.): Diccionario filológico de literatura medieval española: textos y transmisión. Madrid: Castalia, pp. 454-467.

EChEniQue Elizondo, M.a T. (2003): “Pautas para el estudio histórico de las unidades fraseológicas”, in J. L. Girón Alconchel, F. J. Herrero Ruiz de Loizaga, S. Iglesias Recuero y Antonio Narbona Jiménez (eds.): Estudios ofrecidos al profesor José Jesús de Bustos Tovar. Madrid: Editorial Complutense, pp. 545-560.

EChEniQue Elizondo, M.a T. (2018): "Propuesta de un criterio ordenador para un Diccionario histórico fraseológico de la lengua castellana a la luz de factores históricos implicados en la formación de unidades pluriverbales", in M. ${ }^{\mathrm{a}}$ T. Echenique Elizondo, A. Schrott y F. P. Pla Colomer (eds.): Cómo se hacen las unidades fraseológicas. Renovación y continuidad en la diacronía del espacio castellano. Berna: Peter Lang, pp. 409-430. https://doi.org/10.3726/b14461

ECHENIQUE Elizondo, M. T. (2019): "La historia de la lengua española en el estudio de su literatura: pautas para su actualización en el siglo XXI", in C. Strosetzki (ed.): Aspectos actuales del hispanismo mundial. Literatura-Cultura-Lengua. Berlín: $\quad$ DeGruyter, https://doi.org/10.1515/9783110450828-005

FERNÁNDEZ-ORDóÑEZ, I. (2006): "La historiografía medieval como fuente de datos lingüísticos: tradiciones consolidadas y rupturas necesarias", in J J. de Bustos Tovar y J. L. Girón Alconchel (eds.): Actas del VI Congreso Internacional de Historia de la Lengua Española. Madrid: Arco-Libros, pp. 1779-1808.

GASCÓN VERA, E. (1992): “Enrique de Villena: ¿castellano o catalán?”, in Antonio Vilanova (coord.): Actas del $X$ Congreso de la Asociación Internacional de Hispanistas. Barcelona: Promociones y Publicaciones Universitarias, vol. 1, pp. 195-206.

GEIJERSTAM, R. af (1989): “Juan Fernández de Heredia, transmissor de catalanismes lèxics a l'aragonéscastellà?”, in A. Ferrando (ed.): Actes del segon Congrés Internacional de la llengua catalana. València: Universitat de València, pp. 499-511.

GIL, J. (2012): “Latinismos sintácticos en la traducción de la Eneida de don Enrique de Villena”, Boletín de la Real Academia Española XCII/CCCVI, pp. 179-211.

Glare, P. G. W. (1968-1982): Oxford Latin Dictionary. Oxford: Oxford University Press.

GómEz REDondo, F. (2002a): Historia de la prosa medieval castellana. Madrid: Cátedra, t. 3.

Gómez Redondo, F. (2002b): “Crónica de Alfonso XI”, in C. Alvar y J. M. Lucía Megías (dirs.): Diccionario filológico de literatura medieval española: textos y transmisión. Madrid: Castalia, pp. 454-467.

Gómez Redondo, F.; LuCía Megías, J. M. (2002c): "Juan Manuel”, in C. Alvar y J. M. Lucía Megías (dirs.): Diccionario filológico de literatura medieval española: textos y transmisión. Madrid: Castalia, pp. 718723.

GoNZÁLEZ OlLÉ, F. (2004): “Vidal Mayor, texto idiomáticamente navarro”, Revista de Filología Española LXXXIV / 2º, pp. 303-346. https://doi.org/10.3989/rfe.2004.v84.i2.110

Haro Cortés, M. (1996): “Un nuevo testimonio fragmentario de los 'Bocados de oro'”, Revista de Literatura Medieval 8, pp. 9-28.

Haro Cortés, M. (2002): “Bocados de oro”, in C. Alvar y J. M. Lucía Megías (dirs.): Diccionario filológico de literatura medieval española: textos y transmisión. Madrid: Castalia, pp. 224-230.

LACARra, M.a J. (2002): "Barlaam e Josafat”, in C. Alvar y J. M. Lucía Megías (dirs.): Diccionario filológico de literatura medieval española: textos y transmisión. Madrid: Castalia, pp. 205-207. 
LAPESA, R. (1957): La obra literaria del Marqués de Santillana. Madrid: Ínsula.

LAPESA, R. (1981): Historia de la lengua española, 9ạ ed. Madrid: Gredos.

LAPESA, R. (1992 [1980]): “Alma y ánima en el Diccionario histórico de la lengua española: su fraseología”, in J. R. Lodares (ed.): Léxico e Historia, II: diccionarios. Madrid: Istmo, pp. 79-86.

LoREnzo, R. (ed.) (1985): Crónica troiana. A Coruña: Real Academia Galega / Fundación Barrié.

Lucía Megías, J. M. (2002): "Libro del cavallero Zifar”, in C. Alvar y J. M. Lucía Megías (dirs.): Diccionario filológico de literatura medieval española: textos y transmisión. Madrid: Castalia, pp. 773-776.

Morreale, M. (1954): “Un ensayo medieval de exégesis mitológica: los doze trabajos de Hércules de Enrique de Villena”, Revista de Literatura 5, pp. 21-34.

NoRTON, F. J. (1997): La imprenta en España 1501-1520. Ed. anotada, con un nuevo "Índice de libros impresos en España, 1501-1520" por J. Martín Abad. Madrid: Ollero\&Ramos.

PASCUAL, J. A. (ed.) (1974): La traducción de la «Divina Commedia» atribuida a D. Enrique de Villena: estudio y edición del Infierno. Salamanca: Universidad de Salamanca.

Pla Colomer, F. P.; Vicente Llavata, S. (2017): “Aproximación a una fraseología contrastiva en los textos peninsulares de materia troyana: el Libro de Alexandre, la Historia troyana polimétrica y la Crónica troyana de Juan Fernández de Heredia", in M.무 T. Echenique Elizondo y M.- J. Martínez Alcalde (eds.), F. P. Pla Colomer (coord.): La fraseología a través de la historia de la lengua española y su historiografía. València / Neuchâtel: Tirant Humanidades / Université de Neuchâtel, pp. 113-153.

Pla Colomer, F. P.; Vicente Llavata, S. (2018): “Sobre fraseología y fraseometría históricas: la materia troyana en las tradiciones textuales medievales iberorromances", in M. ${ }^{a}$ T. Echenique Elizondo, A. Schrott y F. P. Pla Colomer (eds.): Cómo se hacen las unidades fraseológicas. Renovación y continuidad en la diacronía del espacio castellano. Berna: Peter Lang, pp. 29-54. https://doi.org/10.3726/b14461

Pla Colomer, F. P.; Vicente Llavata, S. (2019): “Estudio fraseológico-contrastivo de textos castellanos y gallego-portugueses de materia troyana”, in M.- Jesús Lacarra (coord.), Nuria Aranda García, Ana M. Jiménez Ruiz y Ángela Torralba Ruberte (eds.): Literatura medieval hispánica «Libros, lecturas y reescrituras». San Millán de la Cogolla: Cilengua, pp. 953-969.

Pla Colomer, F. P.; Vicente Llavata, S. (2020): La materia de Troya en la Edad Media hispánica. Historia textual y codificación fraseológica. Madrid / Frankfurt: Iberoamericana / Vervuert.

RIDRUEJO, E. (1984): “Tres catalanismos (y aragonesismos) sintácticos en 'Los doze trabajos de Hércules' del Marqués de Villena”, Archivo de Filología Aragonesa XXXIV-XXXV, pp. 273-290.

SÁnChez-Prieto Borja, P. (2002): “Fazienda de Ultramar”, in C. Alvar y J. M. Lucía Megías (dirs.): Diccionario filológico de literatura medieval española: textos y transmisión. Madrid: Castalia, pp. 494-497.

SANTIAgo Lacuesta, R. (ed.) (1979): La primera versión castellana de "La Eneida" de Virgilio. Madrid: Real Academia Española.

ViCEnTE LlaVATA, S. (2011): Estudio de las locuciones en la obra literaria de Íñigo López de Mendoza (Marqués de Santillana). Hacia una fraseología histórica del español. València: Universitat de València (Anejo LXXVI de Quaderns de Filologia).

Vicente LlaVATA, S. (2012): “Íñigo López de Mendoza y su secreta labor de codificación fraseológica”, in A. García Valle, A. Ricós Vidal y J. P. Sánchez Méndez (eds.): Fablar bien e tan mesurado. Veinticinco años de investigación diacrónica en Valencia. Estudios ofrecidos a M. ${ }^{a}$ Teresa Echenique Elizondo en conmemoración de su Cátedra. València / Neuchâtel: Tirant Humanidades / Université de Neuchâtel, pp. 87-110. 
Vicente LlaVATA, S. (2013): “Notas de fraseología hispánica medieval. A propósito de la impronta catalanoaragonesa en la obra literaria de don Íñigo López de Mendoza”, in E. Casanova y C. Calvo (eds.): Actas del XXVI Congreso Internacional de Filología y Lingüística Románicas. Berlin: DeGruyter, pp. 431-444. https://doi.org/10.1515/9783110299953.431

Vicente Llavata, S. (2016): “Fraseología hispánica medieval y codificación. A propósito de la traducción aragonesa del Secretum Secretorum promovida por Juan Fernández de Heredia", in M. a T. Echenique Elizondo, M. . J. Martínez Alcalde, J. P. Sánchez Méndez y F. P. Pla Colomer (eds.): Fraseología española: diacronía y codificación. Madrid: CSIC, pp. 75-96.

Vicente Llavata, S. (2017a): “iO vos, dubitantes, creed las istorias e los infortunios de los humanales! Ficción alegórica y modos de "recontar" en los decires narrativos de don Íñigo López de Mendoza", Dicenda. Cuadernos de filología hispánica 35, pp. 325-347. https://doi.org/10.5209/DICE.57714

Vicente Llavata, S. (2017b): “En torno a la voz quartonadas”, Revista de Filología Románica 34/2, pp. 211228. https://doi.org/10.5209/RFRM.58347

ViCENTE LlAVATA, S. (2019a): “Aproximación a la fraseología del aragonés medieval a partir del estudio de la Crónica troyana de Juan Fernández de Heredia”, in C. Strosetzki (coord.): Perspectivas actuales del hispanismo mundial. Literatura-Cultura-Lengua. Münster: wwU Münster, pp. 533-545.

ViCEnTE LlaVATA, S. (2019b): “La expresión del amor en la Crónica troyana de Juan Fernández de Heredia”, in I. Tomasseti (coord.); R. Alviti, A. Garribba, M. Marini, M. Nogúes, I. Turull y D. Vaccari (eds.): Avatares y perspectivas del medievalismo ibérico, San Millán de la Cogolla: Cilengua, pp. 297-307.

Vicente Llavata, S. (2019c): "Hacia una caracterización filológica de Los doze trabajos de Hércules de don Enrique de Villena”, Revista de Literatura Medieval 31, pp. 259-274. https://doi.org/10.37536/RLM.2019.31.0.68718

Vicente Llavata, S. (2020a): "La Grant Crónica de Espanya: reflexiones en torno a la incidencia de los procesos de lexicalización en su edición”, Zeitschrift für romanische Philologie 136/2, pp. 445-474. https://doi.org/10.1515/zrp-2020-0024

Vicente Llavata, S. (2020b): "Estudio de la fraseología en Los doze trabajos de Hércules de don Enrique de Villena”, Nueva Revista de Filología Hispánica 68/2, pp. 641-693. https://doi.org/10.24201/nrfh.v68i2.3653

ViCEnTE LlaVATA, S. (2020c): "Notas en torno al grado de castellanización de la Crónica troyana promovida por Juan Fernández de Heredia en el estudio contrastivo de su fraseología", Vox Romanica 79, pp. 245277. https://doi.org/10.2357/VOX-2020-011

Vicente LlaVATA, S. (2020d): "La Crónica troyana de Juan Fernández de Heredia: escenarios abiertos en el estudio de su fraseología”, RILEX. Revista sobre investigaciones léxicas 3(3) [coord. F. P. Pla Colomer], pp. 73-94. https://doi.org/10.17561/rilex.3.3.5524

VicEnTE LlaVATA, S. (2021): “Lexicalización (y desfraseologización) en la familia fraseológica conformada en torno a la voz nuclear querer", Círculo de Lingüística Aplicada a la Comunicación 85, pp. 153-179. https://doi.org/10.5209/clac.69974

Vicente Llavata, S. (en prensa a): "Notas de fraseología histórica contrastiva. A propósito de la versión castellana (Enrique de Villena, 1427-1428) y catalana (Andreu Febrer, 1429) de la Divina Commedia", Actas del XI Congreso Internacional de Historia de la Lengua Española.

ViCEnTE LlaVATA, S. (en prensa b): "Filología y método en la obra herediana: a propósito de la fraseología", VI Jornadas de Filología Aragonesa. En torno a Juan Fernández de Heredia y su época. En homenaje póstumo a Regina af Geijerstam. 
Vicente Llavata, S. (en prensa c): “Romances hispánicos (y románicos) en la obra de don Íñigo López de Mendoza”, Actas del XX Congreso de la Asociación Internacional de Hispanistas.

Vicente Llavata, S. (en prensa d): “Estudio estilístico de la fraseología en la Crónica troyana (Juan de Burgos, 1490)", Romanische Forschungen.

\section{Notas}

* Este trabajo se inscribe en el proyecto Historia e historiografía de la lengua castellana en su diacronía contrastiva con referencia FFI2017-83688-P, financiado por la Agencia Estatal de Investigación (AEI) y el Fondo Europeo de Desarrollo Regional (FEDER) y gestionado por la Universidad de Valencia a través del Departamento de Filología Española. El proyecto forma parte del Programa Estatal de Fomento de la Investigación Científica y Técnica de Excelencia, Subprograma Estatal de Generación de Conocimiento y está dirigido por la Dra. M. ${ }^{\text {a }}$ Teresa Echenique Elizondo y la Dra.

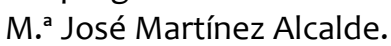

${ }^{1}$ Existe una edición antigua del original en catalán descrita por Norton (1997) con estos datos: $4^{\circ}, 54$ folios, $158 \times 109$ mm, impreso por Cofman el 30 de agosto de 1514 en Valencia, si bien no es posible acceder al texto. Para una descripción de los testimonios en que se conserva, véase Cátedra (2002).

${ }^{2}$ Recordemos su labor de traducción de los grandes autores de la Antigüedad clásica y de la Edad Media. Trabajó para diferentes nobles y, en especial, para Íñigo López de Mendoza, para quien tradujo la Divina Commedia (Pascual Rodríguez 1974) y a quien terminó dedicando su traducción y comentarios de la Eneida (Santiago Lacuesta 1979), que constituye su primera versión romance de la obra de Virgilio.

${ }^{3}$ Aparte de los trabajos reseñados para esta obra, señalamos también otros estudios que se han ocupado de la lengua literaria empleada por Villena en otras de sus obras, como en el caso de Gascón Vera (1992), Eberenz (1995) y Gil (2012). ${ }^{4}$ El hecho de optar por estas combinaciones fraseológicas, y no por otras, supone el resultado de una lectura paralela tanto de la opera prima de Villena como de las versiones peninsulares de materia troyana. Al advertir la recurrencia con que se empleaban estas unidades en todos estos testimonios en secuencias narrativas muy similares nos hizo atisbar un cierto grado de continuidad estilística.

${ }^{5}$ Gómez Redondo (2002a: 2480) trae a colación dos estrofas significativas de la Defunsión de don Enrique de Villena, obra compuesta por don Íñigo López de Mendoza con ocasión de la muerte de su mentor. En ellas el Señor de la Vega nombra a diferentes auctoritates, que convergen, en su sentir, en la figura de Villena: “[...] Perdimos a Libio e al Mantüano, / Macrobio, Valerio, Salustio e Magneo; [...]”. Y afirma: “No se trata sólo de una exhibición de auctoritates, sino de una declaración de ciertos principios humanísticos que don Íñigo quería vincular a la figura de Villena [...]”.

6 “Macrobio, como buen neoplatónico, condena los relatos mitológicos obscenos e inmorales y se vuelve hacia aquellos otros que, "bajo el piadoso velo de la ficción", dan a conocer cosas santas con palabras honestas" (Morreale 1958: XII). 7 Para una visión de conjunto de esta tradición narrativa, véase Lorenzo (1985) y Casas Rigall (1999).

${ }^{8}$ No hay que olvidar que Villena articula cada uno de los doce trabajos en cuatro secciones (historia, alegoría, verdad y aplicación), y la "verdad" trata precisamente de separar lo verdadero de lo ficticio.

9 Igualmente, a lo largo de la traducción y glosas de la Eneida, Villena muestra el interés por la Historia de Guido delle Colonne con numerosas menciones tanto al autor mesinés como a su obra: “ [...] fue fijo menor del Rey acastho, maguer la ystoria troyana non faze mjnçion" (Santiago Lacuesta 1979: 419).

${ }^{10}$ En este artículo no se tendrán en cuenta ni las versiones derivadas del Roman de Troie (c. 1155-1165) de Benoît de SainteMaure, ni las versiones que son resultado de un proceso textual de refundición, como las Sumas de historia troyana (c. 1350) y la Crónica troyana (Juan de Burgos, 1490), pues centramos nuestra hipótesis de trabajo en las versiones directas de la Historia destructionis Troiae (c.1287). Para un estudio estilístico de la fraseología representada en el texto impreso burgalés, véase Vicente Llavata (en prensa d).

${ }^{11}$ Pla Colomer y Vicente Llavata (2017, 2018, 2019 y 2020) han abordado el estudio sistemático de la fraseología en el conjunto de versiones peninsulares de materia troyana en la Edad Media hispánica. 
12 Para la exposición de las citas del texto de Villena, se emplea la última edición preparada por Pedro M. Cátedra, pues constituye "el texto limpio resultante del proceso de edición crítica que, teniendo en cuenta todos los testimonios manuscritos e impresos conocidos, próximamente verá la luz" (Cátedra 2007: 12).

${ }^{13}$ A estos 25 casos hay que añadir 43 más, representados bajo la forma citativa /de un coraçón/.

${ }^{14}$ Para una visión de conjunto sobre la obra herediana, consúltese la monografía de Cacho Blecua (1997). Asimismo, para una reflexión metodológica referida al estudio de la fraseología en el conjunto de la obra herediana, consúltese Vicente Llavata (en prensa b).

15 Los datos referidos a las diferentes obras del corpus herediano se extraen de la base de datos del Hispanic Seminary of Medieval Studies (Gago Jover 2011) cuando no hay ediciones disponibles. En el caso de la Grant Crónica de Espanya, si bien existe una edición modélica del magnum opus herediano (Geijerstam 1964), esta solo recoge los dos primeros libros de la primera partida. En Vicente Llavata (2020a) se reflexionó sobre la incidencia de los procesos de lexicalización, atestiguados en la configuración histórica de las unidades fraseológicas, en el marco de la toma de decisiones asociada al proyecto de edición de la Grant Crónica de Espanya, impulsado por la Universidad de Zaragoza y por Uppsala Universitet.

${ }^{16}$ En el estudio de la fraseología representada en la vulgarización aragonesa del Secretum Secretorum en su contraste con el resto de versiones peninsulares (en castellano, catalán y portugués) de dicho texto latino (Vicente Llavata, 2016), se señalaron algunas innovaciones estilísticas, basadas en la inclusión de piezas fraseológicas representativas del aragonés medieval como es la combinación locucional a çaga, presentes exclusivamente en la versión herediana, e interpretadas como marcas de identidad cultural y lingüística.

17 Todavía en el primer tercio del siglo XVI se documenta una secuencia locucional estrechamente relacionada con ese proceso descrito: "Toda la llave de la buena comunidad está en que sean de un coraçón y una ánima y conformidad en lo de dentro y en lo de fuera” (Francisco de Osuna, Segunda parte del Abecedario espiritual, fechado en 1530).

${ }^{18}$ Todos los datos contextuales de este apartado y de los siguientes referidos a documentación medieval catalana están extraídos del banco de datos Corpus Informatitzat del Català Antic (CICA), que se complementarán con la información cronológica del Diccionari català-valencià-balear (DCVB) y del Diccionari etimològic i complementari de la llengua catalana (DECat.).

19 Estas combinaciones conformadas con el adjetivo posesivo admiten también su posposición, por lo que en la documentación medieval catalana también se recogen realizaciones sintácticas como en companyia sua o en companyia tua.

${ }^{20}$ En otros pasajes de la versión catalana se usan otras combinaciones emparentadas con la descrita como la unidad ab un cor: "Emperò, lo següent dia, lo rey Príam manà tots los troyans venir a parlament; e ells venguts, Eneas, levant-se, amonestà e conseylà que·s tractàs pau ab los grechs, al cual tots los troyans ab un cor consentiren" (Perujo Melgar 2015: 298).

${ }^{21}$ En otro pasaje de esta obra se recoge la variante locucional en una voluntad e querer: "E sabes bien que nosotros somos en grand poderio e que, en cuydado de aquesta vengança, tenemos en conpañja de pujantes señores commo en esto en todo el jnperio de Greçia se leuantara en vna voluntad e querer" (Pelletier Norris 1970: 124).

${ }^{22}$ Si bien el Diccionari català-valencià-balear codifica la voz coratge como sustantivo sinónimo de cor en las acepciones descritas, no recoge estas secuencias locucionales registradas en la versión catalana.

23 Siguiendo las prevenciones expuestas por Sánchez-Prieto Borja (2002: 496) en relación con el texto editado por Lazar (1965), que es la edición utilizada en CORDE, se ha comprobado cada pasaje en la edición reciente de Arbesú (2011).

24 De acuerdo con la descripción codicológica que ofrece Lacarra (2002: 205), los tres testimonios manuscritos en que se conserva la obra se fechan en el siglo $\mathrm{xV}$, si bien "presentan rasgos lingüísticos anteriores y hacen suponer que son copia de otros perdidos".

25 Para una visión actualizada de la biografía de la hija de nuestro autor, véase Cantavella (2015).

${ }^{26}$ La Crónica troyana, al igual que el conjunto de obras que conforman el corpus literario patrocinado por Juan Fernández de Heredia, resulta un texto de enorme interés. Vicente Llavata (2019a, 2019b, 2020c y 2020d) ha analizado su fraseología desde diferentes perspectivas, entre las que se cuenta la de dar respuesta al alto grado de castellanización que muestra en su contraste con el resto de obras heredianas.

27 Si se toman ambas voces por separado, sí que se dan resultados. La combinación prepositiva a consejo de se registra por primera vez en el Libro del cavallero Zifar, de 1300-1305. Por su parte, la unidad a induzimiento de se registra en 1553, en la Segunda parte de la Crónica general de las Indias, de Francisco López de Gómara. 
${ }^{28}$ Señala Lucía Megías (2002: 774): "Por su parte, el copista de $P$, aunque presenta un texto ajeno a tantos errores de copia como sucede en $M$, lleva a cabo una mayor actualización lingüística de su modelo, así como documenta una actitud más innovadora frente al texto en que basa su trabajo; siendo, de este modo, abundantes las enmiendas".

29 "Por su parte, S, como es habitual en la imprenta, resulta a un tiempo conservador con las lecturas de su modelo manuscrito e innovador tanto en el plano lingüístico como en el estilístico, aunque en ningún caso se lleva a cabo una refundición" (Lucía Megías 2002: 774).

${ }^{30}$ En el códice valentino (ms. V-27 de la Biblioteca del Corpus Christi de Valencia) se registra la variante textual <et consello et consello>.

${ }^{31}$ El Nuevo tesoro lexicográfico del español (NTLE 2007: 5750-5751. s.v. induzimiento) recoge esta voz desde el Diccionario latino-español de 1492. Asimismo, incluye la variante induziamiento.

32 El DCECH (1980-1991: I, 62. s.v. aducir) registra por primera vez la voz inducir en el Libro de buen amor de Juan Ruiz bajo la forma verbal de pretérito enduxo. A este respecto, enlazan esta forma con el ast. enducir. Para la forma inducción, ofrece como primera documentación el Vocabulario de Alfonso de Palencia.

33 La primera mención lexicógrafica de la voz induçión se remonta al Universal vocabulario en latín y en romance (1490), de Alfonso de Palencia, lo que sirve también para la forma verbal induzir.

${ }^{34}$ Por el estado lingüístico del documento, con formas como senblant, fer, dito, fuertment, trobavan o present, parece que hay que suponer que se produjo en una modalidad lingüística del Oriente peninsular.

35 También en las Historias contra los paganos se registra la secuencia prepositiva por inducion de: "Mas por indución de algunos qui lo animaron, non lo quiso fazer, antes costrinyó a Sabino, ermando de Vespasiano —el cual aún non se pensava res de mal一, e a todos los otros flavianos encerrarse en el Capitolio [...]" (Romero Cambrón y García Pinilla 2008: 580).

${ }^{36}$ La corónica troyana, en su condición de versión incompleta, traduce el texto latino hasta el libro XIV, por lo que no recoge este contenido, situado en el libro XXI. Asimismo, la versión aragonesa, en razón de su esquematismo narrativo, no desarrolla en forma completa dicho contenido, sino que lo resume.

37 Con las variantes textuales <indigcio $>(B)$ y $<$ induchsio $>(G)$.

${ }^{38}<$ indugcio $>(B)$, <induchcio $>(G)$ e $<$ indiccio $>(M)$.

39 El Oxford Latin Dictionary (s.v. inductiō) codifica esta voz bajo seis acepciones. De todas ellas, nos interesa destacar la acepción tercera 'inducement or prompting to a course of action' en ejemplos como "tantum animi inductio et amor erga Pompeium apud me ualet", perteneciente a la obra Epistulae ad Familiares, de Marco Tulio Cicerón (Glare 19681982: 888).

${ }^{40}$ También para el caso de la combinación prepositiva a pro de, el CORDE ofrece 149 casos. Su primera mención se registra en la Vida de Santo Domingo de Silos, fechada en torno a 1236. Asimismo, el Diccionario del castellano del siglo xV en la Corona de Aragón (DicCA-XV. s.v. pro) registra la expresión compleja a pro, saluamjento e buen entendimjento, registrada en el Fondo Sástago del Archivo de la Corona de Aragón: "vtil e proueytossa puede e deue seyer dito penssado cogitado e entendido a | pro | saluamjento e buen entendimjento vuestro e de·los vuestros toda contrarjedat cessant".

${ }^{41}$ En el caso de la variante en acreçentamiento de, localizada en el Libro de las armas de don Juan Manuel (posterior a 1335), hay que tener en cuenta que el texto se conserva en un códice de finales del siglo xv —ms. 6.376 de la Biblioteca Nacional de Madrid (S) — y en otro datado en el siglo XVI —ms. 19.426 de la Biblioteca Nacional de Madrid — (Gómez Redondo y Lucía Megías 2002: 719-721). Para la variante por acreçentamiento de, localizada en la Gran Crónica de Alfonso XI (c. 1348-1379), hay que tener presente también que las copias conservadas de este texto son posteriores a la fecha de composición; en concreto, se trata de copias del siglo XVI, tal como describe Gómez Redondo (2002b: 282-283). Todo ello nos hace relativizar esas primeras documentaciones de ambos textos.

${ }^{42}$ Las formas gráficas documentadas son las siguientes: <acrecentamiento $\rangle$, <acreçentamiento >, <acrescentamiento>, <acresçentamiento $\mathrm{y}<$ acrezentamiento .

43 El DCECH (1980-1991: Il, 234-235. s.v. crecer) ofrece como primera mención de acrecentamiento el Libro del cavallero Zifar. Asimismo, registran las voces acrecencia y acrecimiento en el Fuero Juzgo (c. 1241).

44 Para este testimonio incluido en CORDE, hay que tener presente lo señalado por Alvar, Fernández-Ordóñez, Gómez Redondo, Hilty y Lucía Megías (2002: 54-80) en referencia al carácter mixto de los materiales alfonsíes y postalfonsíes en su proceso de compilación. 
45 De acuerdo con las consideraciones expuestas en Campa Gutiérrez (2003: 144-145), la crítica ha acreditado que la Crónica de veinte reyes forma parte de la familia de manuscritos que transmite la Versión crítica de la Estoria de España. Si bien este texto cronístico se conserva en doce manuscritos, el texto que se proporciona en coRDE está basado en el testimonio N -Biblioteca del Monasterio de El Escorial (Madrid): Y-I-12 (olim. II.N.7 y I.D.11)—, datado en el siglo XV. Por tanto, aunque se propone una fecha de composición en torno a 1282-1284, los datos lingüísticos podrían reflejar un estado de lengua posterior.

${ }^{46}$ Tal como señalan Alvar, Fernández-Ordóñez, Gómez Redondo, Hilty y Lucía Megías (2002: 42-54), la tercera parte de la General Estoria no se conserva en ningún testimonio original emanado de la corte regia alfonsí, sino que se ha transmitido en cinco testimonios manuscritos posteriores, que abarcan un tramo temporal desde comienzos del siglo XIV hasta principios del XVI.

47 El DCECH (1980-1991: II, 234-235. s.v. crecer) ofrece como primera mención la obra Setenario (c. 1250).

${ }^{48}$ Ms. 1.866: Biblioteca Universitaria de Salamanca.

49 Precisamente, Gascón Vera (1992: 202) ve paralelismos evidentes entre Los doze trabajos de Hércules y algunas de las producciones lulianas, como el Libre de les maravelles del món (1289) o el Libre de l'orde de cavalleria (c. 1275).

${ }^{50}$ No se recoge este pasaje ni en la versión aragonesa ni en la versión castellana incompleta por las razones aducidas en la nota 36 .

51 Presentan aquí especial interés las palabras siguientes de Echenique Elizondo (2019: 93-94): “Para trabajar la lengua de Heredia hay que atender en un principio a los dominios lingüísticos aragonés, navarro, castellano, catalán y occitano, por lo menos (también más tarde para Íñigo López de Mendoza, aunque en Santillana más como referencia erudita que realidad, pues el aragonés era el instrumento de trabajo y el objetivo de Heredia), amén del acercamiento a otras lenguas a través de las traducciones. No es ocioso vincular a ambas figuras, pues sabemos del contacto directo del Marqués con los textos

heredianos [...] y ello puede llegar a aportar frutos de interés desde la perspectiva de la convivencia de lenguas en su obra".

52 Si exceptuamos los cinco registros de la variante con mano fuert correspondientes a la Fazienda de Ultramar, texto que, como se ha apuntado, presenta una heterogeneidad lingüística evidente.

53 Como en el caso de la unidad fraseológica a quarteles (Vicente Llavata 2013 y 2017a) o de la voz quartonadas (Vicente Llavata 2017b), documentadas, respectivamente, en la Comedieta de Ponça y en el Villancico a sus fijas loando su fermosura. Para una visión de conjunto de la fraseología representada en la obra literaria de don íñigo López de Mendoza, consúltese Vicente Llavata (2011, 2012 y en prensa c).

54 Tal como nos recuerda el propio Pedro de Chinchilla en el proemio de su traducción: "E bien creo que algunos avrá que mi inçuficiencia saben dexarán de leer esta trasladación, pero considerando como el ya nonbrado mi señor al occio muy poco se dé, e todo o lo más de su tiempo ocupe con vertuoso e alto deseo en ver e saber la vida e costunbres de los antiguos varones, especialmente de los cavalleros famosos que en el uso e exercicio de las armas virtuosamente se ovieron [...] (Peláez Benítez 1999: 116). 